IZA DP No. 9746

China's Family Planning Policies and Their Labor Market Consequences

Fei Wang

Liqiu Zhao

Zhong Zhao

February 2016 


\title{
China's Family Planning Policies and Their Labor Market Consequences
}

\author{
Fei Wang \\ Renmin University of China \\ Liqiu Zhao \\ Renmin University of China \\ Zhong Zhao \\ Renmin University of China \\ and IZA
}
Discussion Paper No. 9746
February 2016

\author{
IZA \\ P.O. Box 7240 \\ 53072 Bonn \\ Germany \\ Phone: +49-228-3894-0 \\ Fax: +49-228-3894-180 \\ E-mail: iza@iza.org
}

\begin{abstract}
Any opinions expressed here are those of the author(s) and not those of IZA. Research published in this series may include views on policy, but the institute itself takes no institutional policy positions. The IZA research network is committed to the IZA Guiding Principles of Research Integrity.

The Institute for the Study of Labor (IZA) in Bonn is a local and virtual international research center and a place of communication between science, politics and business. IZA is an independent nonprofit organization supported by Deutsche Post Foundation. The center is associated with the University of Bonn and offers a stimulating research environment through its international network, workshops and conferences, data service, project support, research visits and doctoral program. IZA engages in (i) original and internationally competitive research in all fields of labor economics, (ii) development of policy concepts, and (iii) dissemination of research results and concepts to the interested public.
\end{abstract}

IZA Discussion Papers often represent preliminary work and are circulated to encourage discussion. Citation of such a paper should account for its provisional character. A revised version may be available directly from the author. 


\section{ABSTRACT \\ China's Family Planning Policies and Their Labor Market Consequences*}

China initiated its family planning policy in 1962 and one-child policy in 1980 and allows all couples to have two children as of $1^{\text {st }}$ January, 2016. This paper systematically examines the labor market consequences of China's family planning policies. First, we briefly review the major historical evolution of China's family planning policies. Second, we investigate the effects of these policies on the labor market, focusing on the size and quality of the workingage population and its age and gender composition and paying special attention to regional as well as rural-urban differences in the demographic structure resulting from the interaction of the family planning policies and internal migration. Last, we discuss undergoing and prospective policy changes and potential consequences. Though urban areas and coastal provinces have implemented stricter family planning policies, our analysis shows that because of internal migration, the aging problem is more severe in rural areas and in inland provinces. Our simulation results further indicate that the new two-child policy may be too late and too little to alleviate the aging problem in China.

JEL Classification: J13, J11, J21, J61

Keywords: One-Child Policy, aging, sex ratio, quantity-quality model, migration

Corresponding author:

Zhong Zhao

School of Labor and Human Resources

Renmin University of China

59 Zhongguancun St.

Beijing 100872

China

E-mail: mr.zhong.zhao@gmail.com

\footnotetext{
* We would like to thank Klaus Zimmerman for suggesting this line of research. Liqiu Zhao acknowledged the financial support from the Natural Science Foundation of China (Grant No. 71403286). Zhong Zhao acknowledged financial support from the Special Fund for Building WorldClass Universities and Disciplines through the Renmin University of China (Grant No. 16XNL005). All views and the remaining errors are the authors' alone.
} 


\section{Introduction}

China's family planning policies are one set of the most fundamental social policies in China and are more complex than the simplified notion of a one-child policy. The Chinese government initiated the family planning policies in 1962; the well-known one-child policy had only been implemented since 1980. Even after 1980, there were considerable regional and ethnic variations as well as many changes, notably, the exemption of the ethnic minorities and relaxation of the strict one-child policy in rural China in the mid-1980s. Since $1^{\text {st }}$ January, 2016, China formally changed its one-child policy to a two-child policy, i.e., all couples are allowed to have two children.

The more than 50-year-old family planning policies inevitably have affected many aspects of Chinese society. The policies have a far-reaching impact on population size, fertility rate, sex ratio, age structure, family size, and so on. In this paper, we systematically examine the labor market consequences of the China's family planning policies. ${ }^{1}$

First, we briefly review the major historical evolution of China's family planning policies up until 2015. On the one hand, this part provides an institutional background for our study; on the other hand, we construct detailed policy variations across provinces and over time based on various local legal and administrative documents to facilitate future studies.

Second, we examine the impact of family planning policies on the Chinese population structure, labor force and labor market, and focus on fertility effects, sex ratio of the population, age and gender composition of the labor force, quality of the working-age population and labor supply effects resulting from the policies.

Third, we investigate how the regional and rural-urban variations in family planning policies affect internal migration, especially the flow of migrant workers, and how internal migration impacts the regional and rural-urban population structure. Though urban areas and coastal provinces have implemented stricter family planning

\footnotetext{
${ }^{1}$ Part of the paper is drawn from the current literature, and we cite the sources and references in relevant places; part of the paper is our original research, which intends to fill important gaps in the literature.
} 
policies, our analysis shows that because of internal migration, the aging problem is instead more severe in rural areas and in inland provinces. Our results highlight the greater challenge faced by rural areas and inland provinces to overcome aging problem because rural areas and inland provinces are usually less developed, have less resources for social security, including old-age support, and have been losing prime-age population to the urban areas and coastal provinces.

Last, we discuss the current two-child policy and future policy options. Our simulations show that the new two-child policy is far from pulling China out of ageing. Our results further indicate that the abolishment of the birth quota would better address the aging problem than the two-child policy but may not be enough.

According to knowledge regarding pro-natal policies from four regions, Japan, Singapore, South Korea and Taiwan, which have a similar culture to China, China should take pro-natal action as soon as possible. Otherwise, it could be too late when fertility rates have already been at low levels for this long.

\section{History of China's Family Planning Policies}

\subsection{Policies before the One-Child Policy (1963-1979)}

Chinese society stabilized after its civil war ended in 1949, and sterilization and abortion were under strict control thereafter. As a result, China experienced a sizable population growth at the beginning of the 1950s. Consequently, the restrictions over sterilization and abortion were removed in mid-1950s. However, family planning policies were never formally made during this period. Birth rates fell drastically amid a great famine in 1959-1961, followed by a dramatic fertility increase in 1962, which directly pushed the central government of China to issue an administrative document regarding family planning at the end of 1962. This document marked the beginning of China's family planning policies (Liang, 2014).

Instructed by the document, other than the provision of family planning knowledge and technologies, local authorities of China also set birth quotas that were not strictly enforced. Tian (2009) summarized that the policy of the 1960s 
discouraged a couple to have more than three births in a number of provinces. The birth quota became stricter in the 1970s, from three to two, accompanied by more stringent enforcement. In addition to the birth quota, late marriage and long birth spacing were also underscored by the policy of the $1970 \mathrm{~s}^{2}$

As the birth quota and its enforcement became stricter over time, the areas covered by the policy became broader. In the 1960 s, policies were mainly effective in selected cities, while the policies covered both urban and rural areas in the 1970s, with urban enforcement being stronger than rural. ${ }^{3}$ In 1963-1979, family planning policies were only implemented for the ethnic majority, the Han Chinese. Table 1 summarizes birth quotas in 1963-1979 by hukou status and the ethnicity of the population.

Table 1. Birth Quota by Hukou and Ethnicity, 1963-1979

\begin{tabular}{lll}
\hline & $1963-1970$ & $1971-1979$ \\
\hline Urban Han & Three & Two \\
\hline Rural Han & No birth quota & More than two \\
\hline Urban Non-Han & No birth quota & No birth quota \\
\hline Rural Non-Han & No birth quota & No birth quota \\
\hline
\end{tabular}

Note: 1 . The authors' own compilation from various legal and administrative document.

2. Han is the ethnic majority in China.

\subsection{One-Child Policy (1980-2015)}

The strictest one-child policy was initiated in $1980 .{ }^{4}$ At the beginning of the 1980s, each Han Chinese couple could only have one child, and most ethnic minorities were not subject to the birth quota. However, in the very beginning, rural residents tended to violate the birth quota despite of harsh penalties because they preferred sons and larger families. As a result, beginning in the mid-1980s, the one-child policy was gradually relaxed by allowing a rural couple to have a second birth if the first was a daughter. Other than ethnic minorities and rural couples whose first birth was a daughter, couples were also allowed to have a second birth if one or

2 The policy in the 1970s is also known as the "Later, Longer and Fewer" policy.

3 Nevertheless, Wang (2015) indicates that the exact provincial variations of the family planning policies in 1963-1970 are inconsistently summarized in the literature.

${ }^{4}$ Many studies treated 1979 as the starting year, e.g., Cameron et al. (2013) and Liang (2014). 
both partners are only children. ${ }^{5}$

Ebenstein $(2008,2010)$ constructed three measures of the intensity of the one-child policy: monetary penalties due to violating the birth quota, monetary bonuses for having only one child, and birth quota. Particularly, the first has been widely used in the literature to measure the strength of the enforcement of the one-child policy (Ebenstein, 2010; Huang et al., 2015; Huang and Zhou, 2015). The fine rates formulated in years of household income by province and year (1979-2000) are constructed by Ebenstein (2010) based on the fine rates collected by Scharping (2003). The provincial average fine rates depend on provincial regulations, ethnic composition, and the share of parents with urban registration (Ebenstein, 2010). Appendix Figure 1 in Appendix B plots the fertility penalty from 1980-2000 in each province. Though fines in different provinces follow different patterns, the average level of fines was higher in the 1990s than in the 1980s, implying stricter policy enforcement in the 1990s.

The birth quota measured by Ebenstein $(2008,2010)$ was relatively rough and only varies by province. Table 2 lists the initial years when specific populations in a province were allowed to have a second birth and may help construct a more detailed measure of the birth quota. The years are the earliest possible according to local legal or administrative documents that are available. Therefore, it is possible that some group of people in a province may actually be allowed to have a second birth earlier than the listed years.

Table 2 implies that the initial years of policy relaxation were generally earlier for rural residents than for urban residents. In other words, at one point in time, birth quotas were more stringent for the urban population than for the rural population. Ethnic minorities, rural couples whose first birth was a daughter, and couples who are both only children were allowed to have a second birth earlier than couples in which only one partner was an only child, who were generally allowed to have a second birth around 2014.

\footnotetext{
${ }^{5}$ Couples may also be allowed to have a second birth if the first birth was disabled, they remarried, or they were infertile for a long time and became fertile after they had an adopted child, and so on. Rules are different over time and across regions.
} 
Table 2. Initial Years of Being Allowed to Have a Second Birth, by Province and Specific Population Group

\begin{tabular}{|c|c|c|c|c|c|c|c|}
\hline \multirow[t]{2}{*}{ Province } & \multicolumn{2}{|c|}{ Ethnic minorities } & \multirow{2}{*}{$\begin{array}{c}\begin{array}{c}\text { First birth } \\
\text { was daughter }\end{array} \\
\text { Rural }\end{array}$} & \multicolumn{2}{|c|}{$\begin{array}{c}\text { Both partners } \\
\text { are only children }\end{array}$} & \multicolumn{2}{|c|}{$\begin{array}{l}\text { One partner } \\
\text { is only child }\end{array}$} \\
\hline & Rural & Urban & & Rural & Urban & Rural & Urban \\
\hline Anhui & 1981 & 1981 & 1988 & 1984 & 1984 & 1988 & 2014 \\
\hline Beijing & 1983 & 1983 & 1991 & 1983 & 1991 & 2014 & 2014 \\
\hline Chongqing & 1987 & 1987 & 1987 & 1987 & 1987 & 2014 & 2014 \\
\hline Fujian & 1988 & N.A & 1988 & 1988 & 1988 & 1988 & 2014 \\
\hline Guizhou & 1988 & 1988 & 1998 & 1988 & 1988 & 2014 & 2014 \\
\hline Guangdong & 1986 & N.A & 1986 & 1986 & 1986 & 2014 & 2014 \\
\hline Guangxi & 1994 & 1994 & 1994 & 1994 & 1994 & 2014 & 2014 \\
\hline Gansu & 1985 & 1985 & 1990 & 2002 & 2002 & 2014 & 2014 \\
\hline Hainan & 1989 & 1989 & 1989 & 1989 & 1989 & 2014 & 2014 \\
\hline Henan & 1990 & N.A & 1990 & 2011 & 2011 & 2014 & 2014 \\
\hline Hubei & 2009 & N.A & 1988 & 2009 & 2009 & 2014 & 2014 \\
\hline Hunan & 1990 & N.A & 1990 & 1990 & 1990 & 2014 & 2014 \\
\hline Hebei & 1982 & 1989 & 1989 & 1982 & 1989 & 2014 & 2014 \\
\hline Heilongjiang & 1990 & 1990 & 1990 & 1990 & 1990 & 2014 & 2014 \\
\hline Jiangsu & N.A & N.A & 1990 & 1990 & 1990 & 1990 & 2014 \\
\hline Jiangxi & 1990 & 1990 & 1990 & 1990 & 1990 & 2014 & 2014 \\
\hline Jilin & 1988 & 1988 & 1988 & 1988 & 1988 & 2002 & 2014 \\
\hline Liaoning & 1988 & N.A & 1988 & 1988 & 1988 & 1988 & 2014 \\
\hline Neimenggu & 1990 & 1990 & 1990 & 2002 & 2002 & 2014 & 2014 \\
\hline Ningxia & 1982 & 1986 & 1982 & 1982 & 1986 & 1982 & 2014 \\
\hline Qinghai & 1982 & 1992 & 1982 & 1982 & 1992 & 1982 & 2014 \\
\hline Sichuan & 1987 & 1987 & 1987 & 1987 & 1987 & 2014 & 2014 \\
\hline Shanxi & 1990 & 1990 & 1990 & 1990 & 1990 & 1990 & 2014 \\
\hline Shandong & 1988 & 1988 & 1988 & 1988 & 1988 & 2014 & 2014 \\
\hline Shanghai & 1992 & 1992 & N.A & 1990 & 1990 & 1990 & 2014 \\
\hline Shaanxi & 1981 & 1981 & 1991 & 1986 & 1986 & 2014 & 2014 \\
\hline Tianjin & 1988 & 1988 & 1988 & 1988 & 1988 & 1988 & 2014 \\
\hline Xinjiang & 2002 & 2002 & 2002 & 2002 & 2002 & 2002 & 2013 \\
\hline Xizang & 1992 & 1992 & N.A & 1992 & 1992 & 2014 & 2014 \\
\hline Yunnan & 1991 & 2015 & 1991 & 1991 & 1991 & 2015 & 2015 \\
\hline Zhejiang & 1990 & 1990 & 2002 & 1989 & 1989 & 2014 & 2014 \\
\hline
\end{tabular}

Notes: 1. The authors' own construction based on various local legal and administrative documents.

2. "N.A" indicates that relevant policies were not found in local documents. 


\section{Family Planning Policies and China's Labor Markets}

\subsection{Family Planning Policies, China's Population and Labor Force}

\subsubsection{The Fertility Effects of Family Planning Policies}

Although China's population has been growing steadily over the last six decades, the population growth rate dropped sharply from more than $2.5 \%$ in the late 1960s to $0.5 \%$ in 2010 (see Figure 1). The slowed growth in population is mainly due to the remarkable drop in fertility. The total fertility rate in China declined from more than 6 to 1.65 children per woman from the late 1960s to 2010 (see Figure 2). Most of the decline occurred during the 1970s, with the "Later-Longer-Fewer" family planning campaign. Research on China's fertility decline has stressed the importance of family planning policies while simultaneously acknowledging the influence of socioeconomic development and cultural factors (Birdsall and Jamison, 1983; Bongaarts and Greenhalgh, 1985; Cai, 2010; Cooney, Wei, and Powers, 1991; Feeney et al., 1989; Poston and Gu, 1987; Tien, 1984; Wolf, 1986).

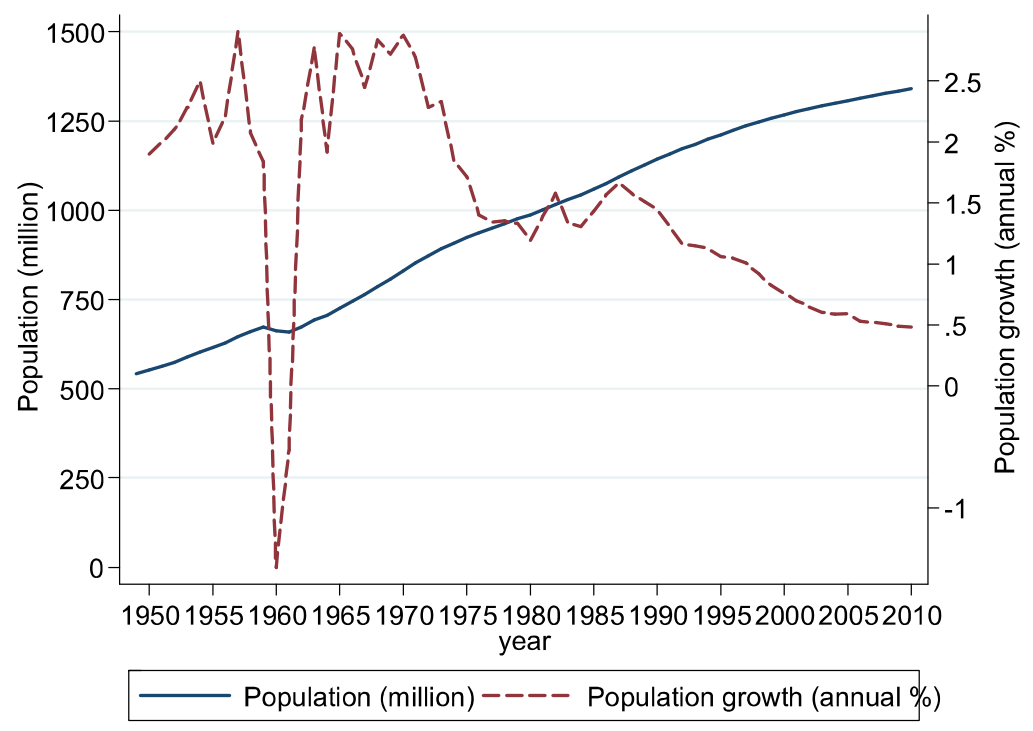

Figure 1: Population and Population Growth Rate in China: 1949-2010

Note: The authors' own calculation from China Statistical Yearbook (various years). 


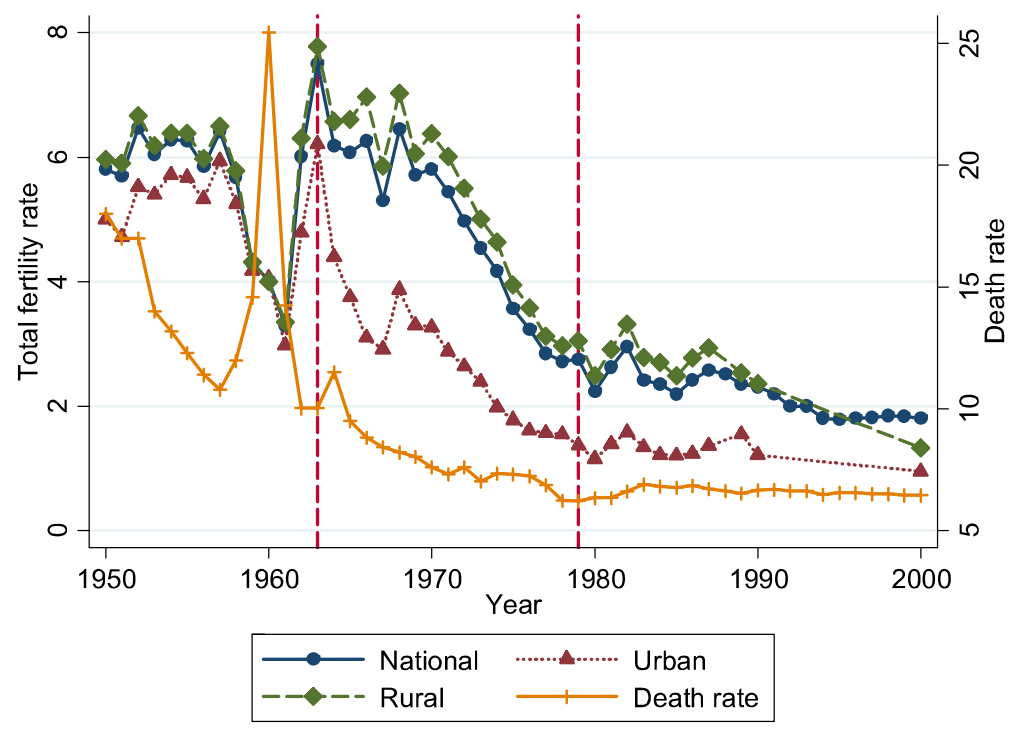

Figure 2: Total Fertility Rate: China Nationwide, Urban and Rural 1950-2000

Sources: 1950-1981: One-per-thousand fertility survey conducted in 1982 (China Population Information Center, 1984); 1982-88: Data from the two-per-thousand fertility and contraceptive survey conducted by the State Family Planning Commission in 1988, provided by the Planning and Statistical Department of the SEPC, China Population Newsletter, 6(2), (1989). The total fertility rates for urban and rural areas in 1990 and 2000 are calculated based on the 1990 and 2000 Chinese Population Census (1\% sample). The death rate is from the China Population and Employment Statistics Yearbook (various years).

Some studies argue that family planning policies explain a sizable portion of China's fertility decline (Lavely and Freedman, 1990; Yang and Chen, 2004 and Li et al., 2005). For example, Li et al. (2005) find that the one-child policy has had a large effect on fertility. The average effect on the post-treatment cohorts on the probability of having a second child is as large as -11 percentage points. Moreover, the effects of the family planning policies on fertility have generally become stronger over time and are larger for urban populations and the Han Chinese (Wang, 2015).

Though family planning policies have a statistically significant effect on fertility, most studies find that the policies explain only a small amount of the variations in fertility (Schultz and Zeng, 1995; McElroy and Yang, 2000). A large portion of the decline of fertility can be attributed to broad socioeconomic developments (Schultz and Zeng, 1995; Zhang, 1990), for example, women's schooling, household income and the shift in the labor force from agricultural activity to industrial production. McElroy and Yang (2000) also find that the fertility effect of the family planning policies is small, and a complete removal of the existing monetary penalties imposed 
on "above-quota births" in rural China only results in a relatively small increase in fertility of 0.33 births per woman. The additional effects of the one-child policy are limited (Wang, 2015).

\subsubsection{The Sex-ratio Effects of Family Planning Policies}

The sex ratio at birth has dramatically increased from 108.5 in 1982 to 117.96 in 2010, deviating far from the biologically stable range from 103 to 107 (NBS, 2012). ${ }^{6}$ The high sex ratios in China have concerned researchers, and the cause for the increase in sex ratios has been in debate. A number of economists and demographers argue that the one-child policy is responsible for the increase in sex ratios in China (e.g., Zeng et al., 1993; Das Gupta, 2005; Ebenstein, 2010; Li et al., 2011). Figure 3 depicts the time series of sex ratios by birth cohort from 1965 to 2000 projected by the Chinese population census in 1982, 1990 and 2000. The sex ratio in the pre-policy change period, i.e., before 1979 (approximately 106), is significantly lower than that in the post-policy change period. The one-child policy increased the sex ratio by approximately 7.0 for the birth cohort of 1991-2005, which accounts for about $55 \%$ of the total increase in the sex ratio (Li et al., 2011).

The increase in the sex ratio in China is the result of a combination of son preference, the progress of gender-selection technology and a decrease in fertility induced by the one-child policy (Ebenstein, 2010; Li et al., 2011). As a patrilineal society, son preference is deeply rooted in traditional Chinese culture. Most parents have a very strong desire to have at least one son. With the facilitation of modern gender-selection technologies, such as ultrasound B machines, parents may engage in sex selection in the face of fertility restrictions induced by the one-child policy. Particularly, Ebenstein (2010) shows that the overall increase in the sex ratio is driven by an increase in the prevalence of sex selection among the first and second births. ${ }^{7}$

\footnotetext{
6 The sex ratio is defined as the number of males per 100 females.

7 The increased sex ratio of first births and second births is responsible for 5.7 million of the 5.9 million increase in "missing girls" observed in the census, or $97 \%$ percent of the total change (Ebenstein, 2010).
} 


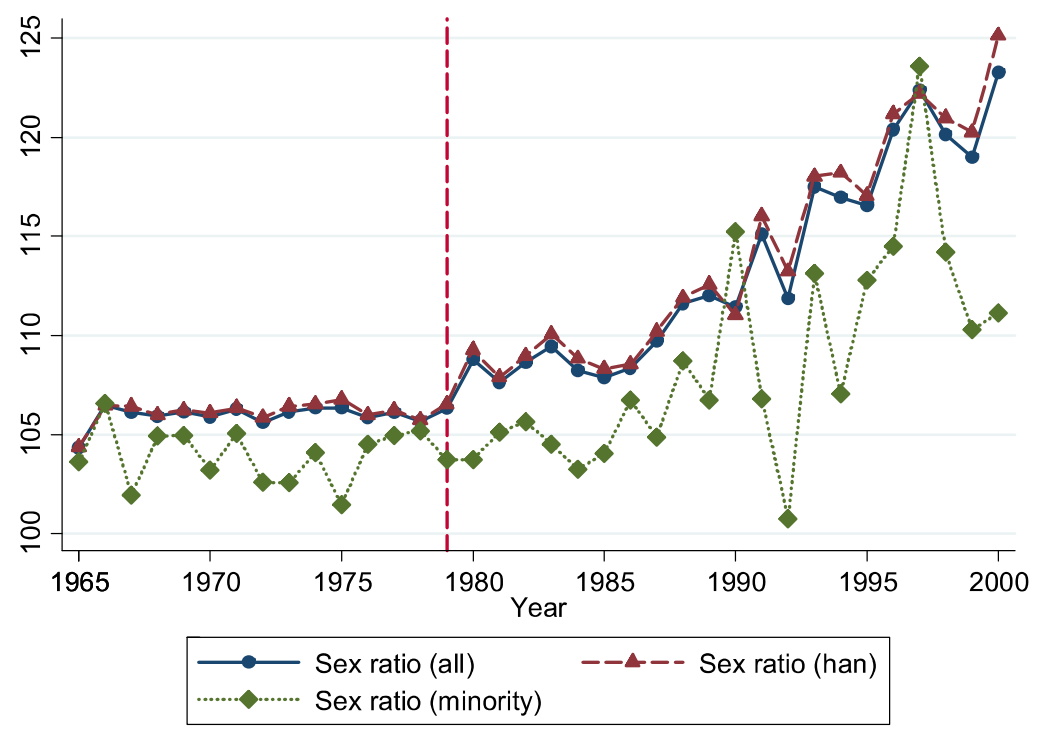

Figure 3: Sex ratios by birth cohorts

Notes: The authors' own calculation based on the 1982, 1990 and 2000 Chinese Population Census (1\% sample).

As the enforcement of the one-child policy varies across regions, there are remarkable regional differences in sex ratios. Regions with more stringent enforcement of the family planning policy have more aggressive sex-selective abortions and, as a result, a more skewed sex ratio. Nevertheless, the imbalanced sex ratios are less severe in some western provinces and in most ethnic autonomous regions where family planning policies have not been rigorously implemented (See Figure 3). For instance, the sex ratio at birth in Xinjiang province in 2010 is 106.02; however, it is up to 128.65 in Anhui province.

Note that the reported sex ratios are likely to be upward biased because of the excess daughter under-reporting (Ebenstein, 2010; Goodkind, 2011). Since the early 1970s, parents who violate birth restrictions have been subjected to fines and penalties (Bongaarts and Greenhalgh, 1985; Lavely and Freedman, 1990; Michelson, 2010; Zeng, 2007). The penalties provide a strong incentive for both parents and officials to under-report out-of-quota daughters. Thus, the official sex ratios tend to be upward biased and should be interpreted with caution. 


\subsubsection{The Policy Effects on the Age and Gender Composition Evolution of the Working-Age Population}

The dramatic drop in the total fertility rate during the 1970s has resulted in reduced numbers of people newly entering the workforce in the 1990s and beyond. Figure 4 presents factual and counterfactual population pyramids for the male and female populations in 1990, 2000 and 2010, respectively. ${ }^{8}$ The unfilled bars with black lines refer to the factual population pyramids. The gray bars denote the pyramids under the counterfactual regime in which no family planning policies take place, i.e., no "Later-Long-Fewer" campaign and one-child policy. The factual pyramids in Figure 4 show a low number of births between the mid-1970s and mid-1980s. The working-age population aged 15 to 64 years was 973.3 million in 2010, which accounted for $74.5 \%$ of total population, higher than that of many developed and developing countries. ${ }^{9}$ The share of the working-age population peaked in 2010 and started to decline afterwards. The working-age population in China has begun to shrink. The declining labor force growth has caused labor shortages and thus has increased wages (Li et al., 2012). The labor shortage and rising wages are particularly evident in most coastal regions, such as the Pearl River Delta and the Yangtze River Delta areas, whereas the counterfactual age structure in Figure 4 is pyramid-shaped with a broad base of young generations, indicating that China's working-age population would not have shrunk without family planning policies.

Another key feature of the evolution of the working-age population is the skewed sex ratio of working-age population as people born after the one-child policy in 1979 enter the workforce in the late 1990s. Besides the imbalanced sex ratio itself, the male-biased sex ratio may lower female labor force participation (Angrist, 2002) as a high sex ratio increases the shadow wage for home production.

\footnotetext{
8 The calculated age structure for year 1990, 2000 and 2010 is based on the age structure in 1970 projected backward from 1982 population census. The counter-factual fertility rate used for counter-factual simulation is from Wang (2015). The detailed procedure of counterfactual simulations is explained in Appendix C.

9 The working-age population's share increased from $59.3 \%$ in 1980 to $74.5 \%$ in 2011.
} 

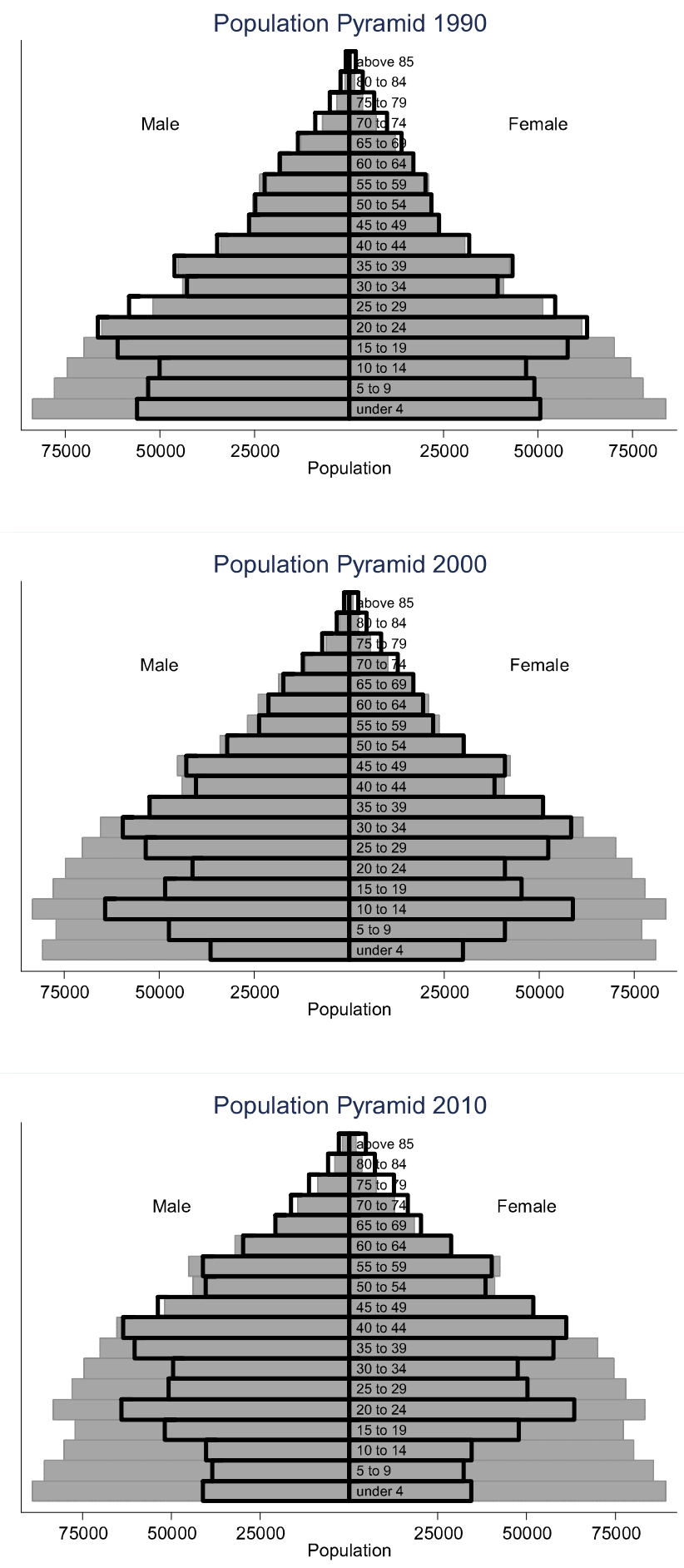

Figure 4: Population Pyramid 1990-2010

Notes: 1. The authors' own calculation based on one percent sample of the 1990, 2000 Population Census data and Tabulation on the 2010 Population Census. The calculated age structure for year 1990, 2000 and 2010 is based on the age structure in 1970 projected backward from 1982 population census. The counter-factual fertility rate used for counter-factual simulation is from Wang (2015).

2. The unfilled bars with black lines refer to the factual population pyramids. The gray bars denote the pyramids under the counterfactual regime in which no family planning policies take place, i.e., no "Later-Long-Fewer" campaign and one-child policy. 


\subsubsection{The Effects of Family Planning Policies on Labor Supply}

The family planning policies induced a decline in fertility in China. Standard economic models predict a negative effect of fertility on female labor supply (Borjas, 2000). Nevertheless, the negative relationship between fertility and labor supply may not exist in developing countries because of the different household structure from that in developed countries. Using twining as a natural experiment, He and Zhu (2015) find a negative, though small, effect of fertility on female labor supply in urban China. However, applying the same identification strategy, Li et al. (2015) show that reducing fertility cannot increase parental labor supply in rural China. The childcare provided by grandparents can mitigate the negative effects of fertility on parental labor supply. Because of the extended family structure, fertility does not significantly affect the labor supply in China. In other words, family planning policies may not contribute to the growth of GDP by stimulating labor supply.

\subsection{Quality of Working-age Population}

\subsubsection{Effects of Family Planning Policies on Human Capital}

The quantity-quality (Q-Q) model of Becker and Lewis (1973) suggests that decreases in the quantity of children will induce more resources to be allocated to each child so that average child quality will increase. The family planning policies in China exogenously reduces the number of children and thus may induce more human capital investment, which plays a major role in the productivity of nations. ${ }^{10,11}$

Human capital has increased substantially in China over the last three decades, with the average years of schooling increasing by approximately $50 \%$ from 5.8 years to 8.9 for an adult aged 25 . Family planning policies may play an important role in promoting human capital. Most empirical studies have found a significant trade-off between number of children and child quality in China and a more pronounced

\footnotetext{
${ }^{10}$ In fact, one of the slogans for China's family planning policies is as follows: Control population size and improve the population quality.

11 First of all, human capital raises the skill level of workers. Secondly, workers with better educations and better skills adapt better relative to low skilled workers to changes in the Chinese economy (Heckman, 2005).
} 
trade-off in rural areas with poor public education system (Li et al., 2008; Rosenzweig and Zhang, 2009; Liu, 2014). However, the contribution of the one-child policy in China to the development of its human capital was modest (Rosenzweig and Zhang, 2009; Liu, 2014). The estimates from Rosenzweig and Zhang (2009) suggest that the one-child policy at most increased schooling attainment by $4 \%$, the probability of attending college by less than $9 \%$, school grades by $1 \%$, and the incidence of good or excellent health by less than $4 \%$. One study finds that the trade-off is stronger if the quality is measured by height (Liu, 2014).

However, few studies reject the quality-quantity trade-off in China. For instance, Qian (2009) finds that having a second child increases the school enrollment rate of the firstborn child in rural China, and she argues that this occurs because of economies of scale in schooling, for example, children from the same family can share text books and clothing.

\subsubsection{Effects of Family Planning Policies on Other Aspects of Quality}

In addition to education and health outcomes, a number of studies investigate the behavioral consequences of being an only child, which is known as "Little Emperor" Syndrome. They find that only children tend to be self-centered, less cooperative, and less likely to get along with peers (Blake, 1981). In addition, only children are less trusting, less trustworthy, more risk-averse, less competitive, more pessimistic, and less conscientious (Cameron et al., 2013).

The family planning policies in China also have an impact on entrepreneurship-specific human capital, and the impact is mixed in the literature. On the one hand, the sex ratio imbalance induced by the one-child policy can promote entrepreneurship (Wei and Zhang, 2011). A rise in sex ratio toughens competition in the marriage market and, as a result, inspires men and parents with a son to find ways to accumulate more wealth. Engaging in riskier activities, for instance, entrepreneurial activities, is one way to achieve the goal. ${ }^{12}$ Thus, the imbalance of sex ratio

\footnotetext{
${ }^{12}$ Entrepreneurship is a higher risk and a higher return activity (relative to being a worker).
} 
stimulates entrepreneurship in China.

On the other hand, being only children may depress entrepreneurship. Cameron et al. (2013) find that only children tend to be more risk-averse. If a willingness to take risks is an important component of entrepreneurship, the results of Cameron et al. (2013) imply that only children are less likely to be entrepreneurs. There has been, however, no direct investigation of how only children impact on the entrepreneurship, which deserves further study.

\section{Interaction of the Family Planning Policy and Internal Migration}

\subsection{Family Planning Policies and Internal Migration}

The age structure of a region is shaped by the processes of fertility, mortality and migration. Before China's economic reforms, which began in 1978, internal migration was strictly controlled, and China was largely under-urbanized. According to China's 1982 census, only $20.8 \%$ of the total population lived in urban areas, which was much lower than the world average estimated by the United Nations as $40.1 \%$ in 1982. After China's economic reforms, the rapid growing demand for unskilled labor in the manufacturing and service industries in urban areas has led to an unprecedented rural-to-urban migration. The large-scale migration since the late 1980s has substantially reshaped the geographic distribution of Chinese population.

In China, the family planning policy has been implemented more rigorously in urban areas and areas with a high proportion of Han Chinese, which would result in a more rapid aging process in these areas. The interaction of the family planning policies and migration in China, however, has reversed the trend of regional aging rate. Regions with more stringent enforcement of the family planning policy have lower fertility rates and thus lower supply of local native workers. Other things being equal, these regions have higher demand for migrant workers. The strict enforcement of family planning policies in urban areas thus has accelerated rural-urban migration. In addition, migrants have migrated to cities for work and thus are mostly young. ${ }^{13}$

\footnotetext{
13 Young workers are more likely to migrate because migration is a human capital investment.
} 
Consequently, a region may grow "younger" if in-migration rate is high.

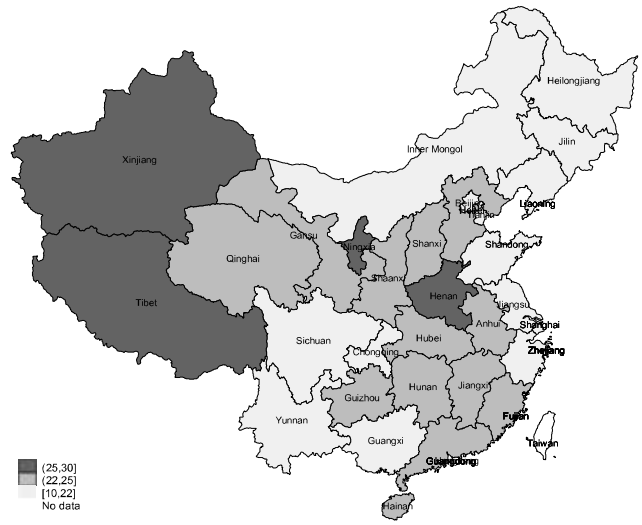

(A) Birth rate in 1989

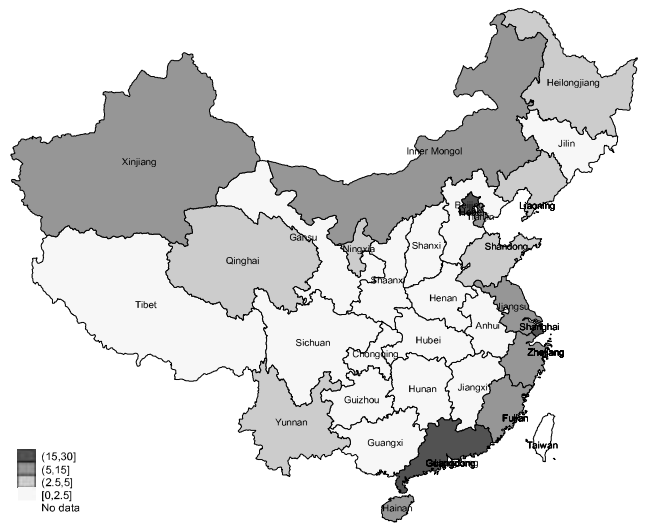

(B) In-migration rate in 2005

Figure 5: Migration and Birth Rate in China

Note: The authors' own calculation from 1990 population census and 2005 mini-census in China.

Figure 5(A) and (B) show the birth rate in 1989 and in-migration rates in 2005, which is defined as the ratio of all migrants who moved into the region relative to the total population in the region at the provincial level. The darkest areas reflect the highest birth rate or the highest in-migration rate. The two graphs in Figure 5 suggest that regions with low birth rate in 1989 have a higher in-migration rate in 2005.

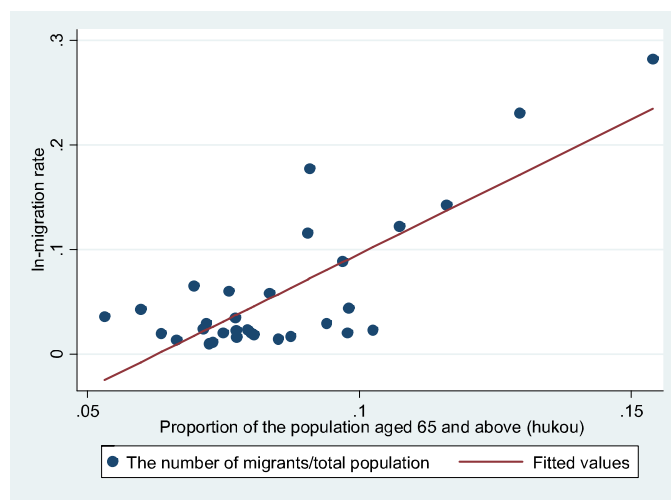

(A) Aging rate of local population and in-migration rate

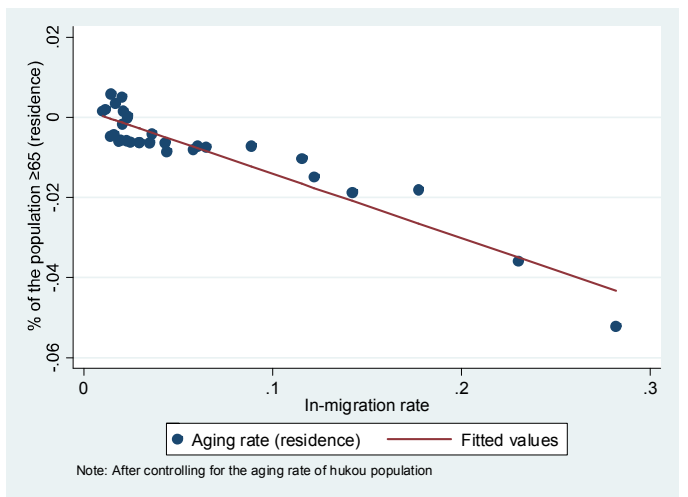

(B) In-migration rate and aging rate of resident population

\section{Figure 6: Aging Rate and In-migration Rate in 2005}

Note: The authors' own calculation from 2005 mini-census.

Figure 6 relates provincial aging rate and in-migration rate. Figure 6(A) indicates that regions with higher aging rate of local native population have a higher 
in-migration rate. Figure 6(B) implies that high in-migration rate of a region can alleviate the aging process of resident population in the region.

We further examine the impact of family planning policies in 1980-1984 when migration was strictly controlled on internal migration in 2005 using the population census in 1990 and mini-census in 2005 in China. The empirical specification is based on the conceptual model of migration flow, presented in Appendix A. The bilateral migration flow depends on the technologies affecting labor productivity, the working-age population and birth rates in the region of origin and destination in the initial period, as well as migration costs. Specifically, we apply the gravity equation of migration, pioneered by Ravenstein (1889), to estimate the impact of family planning policies on internal migration in China. Our unit of analysis is the number of migrants between pairs of prefecture cities.

$$
\begin{aligned}
\operatorname{lnM}_{i j, 1}=\beta_{0}+ & \beta_{1} \text { birth_rate }_{i, 0}+\beta_{2} \text { birth_rate }_{j, 0}+\beta_{3} \operatorname{lnpop}_{i, 0}+\beta_{4} \operatorname{lnpop}_{j, 0} \\
& +\beta_{5} Z_{i, 0}+\beta_{6} Z_{j, 0}+\beta_{7} \text { lndist }_{i j}+\varepsilon_{i j, 1}
\end{aligned}
$$

where $\ln M_{i j, 1}$ denotes the logarithm of migration flow from prefecture city $i$ (region of origin) to $j$ (destination) in 2005. birth_rate ${ }_{i, 0}$ referes to the average number of live births per 1,000 population between 1981-1985 in prefecture $i$. $\operatorname{lnpop}_{i, 0}$ denotes the logarithm of the working-age population (aged 15 to 64) in 1990 in prefecture $i$. The average wage, the share of manufacturing employment and the average years of schooling at prefecture-city level in 1990 are used as proxies for factors affecting labor productivity. Moreover, we include the log distance between the two prefecture cities to control for migration costs. $\varepsilon_{i j, 1}$ is the error term.

Demand shocks (e.g., trade liberalization) and productivity shocks (e.g., the increasing use of computers) in 2005, which affect bilateral migration flow, may also be correlated with the birth rate from 1981-1985. Thus, the coefficient of the birth rate tends to be biased. We apply regional enforcement of the one child policy as the instrument for the birth rate. Because a pregnancy usually lasts for 9 months, parents' decision to have a child, if any, should be made close to a year in advance. We therefore use the enforcement of the one-child policy in 1980-1984 as the instrument 
for the birth rates in 1981-1985. Specifically, the measure of the one child policy in this paper is the average monetary penalty rate for one unauthorized birth in the provincial-level panel from 1980-1984 from Ebenstein (2010). ${ }^{14}$ The fine rates are formulated in years of household income (Ebenstein, 2010; Huang et al., 2015). Though the monetary penalty is one aspect of the policy, it can capture key elements of the variation in the strictness of the policy ( $\mathrm{Gu}$ et al., 2007). As Han Chinese is subject to a strict one-child policy, we interact the fine rates with the ethnic composition (proportion of Han Chinese) at the prefecture-city level.

$$
\begin{aligned}
\text { birth_rate }_{i p, 0} & =\gamma_{0}+\gamma_{1}\left(\text { Fine }_{p,-1} \times \text { Han }_{i p, 0}\right)+\gamma_{2} \text { Fine }_{p,-1}+\gamma_{3} \operatorname{Han}_{i p, 0} \\
& +\gamma_{4} \operatorname{lnpop}_{i, 0}+\gamma_{5} Z_{i, 0}+\gamma_{6} \text { prov }+\gamma_{7} \text { prov } * \text { year }+\gamma_{8} \text { year }+\varepsilon_{i p, 1}
\end{aligned}
$$

where Fine $_{p,-1}$ is the one-child policy fine rate in province $p$ one year ahead of new births. $\operatorname{Han}_{i p, 0}$ denotes the proportion of Han Chinese in prefecture city $i$ province $p$. Province dummies and province-specific time trends are also controlled for in the regression.

The results of gravity equation estimation are reported in Table 3. The first-stage results reported in column (1) indicate that the one-child policy in 1980-1984 has a highly significant effect on birth rates in 1981-1985. As expected, on average, the increase in fine rates significantly decreases the birth rate, and the negative effect of fine rates on birth rates increases with the proportion of Han Chinese. The second-stage results in column (2) suggest that the low birth rate induced by the one-child policy in the destination city stimulates bilateral migration flow. A decrease in the birth rate by 1 live birth raises the in-migration flow by 8.4 percent, whereas the birth rate in the region of origin does not have a significant impact on out-migration flow. In column (3), we further control for the unemployment rate in both source and destination cities in 2005 . The results do not change much.

\footnotetext{
14 The average fine rates are determined by provincial regulations, ethnic composition, and the share of parents with urban registration (Ebenstein, 2010).
} 


\begin{tabular}{|c|c|c|c|}
\hline Variable & $\begin{array}{c}\text { (1) } \\
\text { Birth rate in } \\
1981-1985\end{array}$ & $\begin{array}{c}(2) \\
\text { Log migration } \\
\text { flow } \\
\end{array}$ & $\begin{array}{c}(3) \\
\text { Log migration } \\
\text { flow }\end{array}$ \\
\hline Fine & $\begin{array}{c}7.08 * * * \\
(2.57)\end{array}$ & & \\
\hline Fine $\times$ Han & $\begin{array}{c}-10.31 * * * \\
(2.48)\end{array}$ & & \\
\hline Han & $\begin{array}{c}12.35 * * * \\
(2.75)\end{array}$ & & \\
\hline Birth rate 1981-1985 (destination) & & $\begin{array}{c}-0.084 * * * \\
(0.0068)\end{array}$ & $\begin{array}{c}-0.081 * * * \\
(0.0068)\end{array}$ \\
\hline Birth rate 1981-1985 (source) & & $\begin{array}{l}-0.0037 \\
(0.011)\end{array}$ & $\begin{array}{l}-0.0041 \\
(0.011)\end{array}$ \\
\hline Log wage 1985 (destination) & $\begin{array}{c}-2.77 * * * \\
(0.73)\end{array}$ & $\begin{array}{c}0.76^{* * *} \\
(0.028)\end{array}$ & $\begin{array}{c}0.81 * * * \\
(0.030)\end{array}$ \\
\hline Log wage 1985 (source) & & $\begin{array}{c}-0.11 * * * \\
(0.036)\end{array}$ & $\begin{array}{c}-0.12 * * * \\
(0.036)\end{array}$ \\
\hline Log working-age pop in 1990 (destination) & $\begin{array}{c}-0.024 * * * \\
(0.14)\end{array}$ & $\begin{array}{l}0.14 * * * \\
(0.0051)\end{array}$ & $\begin{array}{l}0.13 * * * \\
(0.0052)\end{array}$ \\
\hline Log working-age pop in 1990 (source) & & $\begin{array}{l}0.12 * * * \\
(0.0048)\end{array}$ & $\begin{array}{l}0.12 * * * \\
(0.0048)\end{array}$ \\
\hline Average education in 1990 (destination) & $\begin{array}{c}-1.57 * * * \\
(0.16)\end{array}$ & $\begin{array}{c}-0.075^{* * *} \\
(0.012)\end{array}$ & $\begin{array}{c}-0.058^{* * *} \\
(0.011)\end{array}$ \\
\hline Average education in 1990 (source) & & $\begin{array}{c}0.00059 \\
(0.018)\end{array}$ & $\begin{array}{l}-0.0017 \\
(0.018)\end{array}$ \\
\hline$\%$ of employment in manu in 1982 (destination) & $\begin{array}{c}-11.91 * * * \\
(1.56)\end{array}$ & $\begin{array}{c}0.78 * * * \\
(0.12)\end{array}$ & $\begin{array}{c}0.87 * * * \\
(0.12)\end{array}$ \\
\hline$\%$ of employment in manu in 1982 (source) & & $\begin{array}{l}-0.018 \\
(0.14)\end{array}$ & $\begin{array}{l}-0.030 \\
(0.14)\end{array}$ \\
\hline Log distance & & $\begin{array}{l}-0.36 * * * \\
(0.0070)\end{array}$ & $\begin{array}{l}-0.36 * * * \\
(0.0070)\end{array}$ \\
\hline Unemployment rate in 2005 (destination) & & & $\begin{array}{c}-1.35 * * * \\
(0.16)\end{array}$ \\
\hline Unemployment rate in 2005 (source) & & & $\begin{array}{c}0.18 \\
(0.12)\end{array}$ \\
\hline Constant & $\begin{array}{l}-744.69 \\
(876.93) \\
\end{array}$ & $\begin{array}{c}-3.22 * * * \\
(0.61)\end{array}$ & $\begin{array}{c}-3.56^{* * *} \\
(0.61)\end{array}$ \\
\hline Observations & 1,150 & 44,101 & 44,101 \\
\hline R-squared & 0.61 & 0.348 & 0.350 \\
\hline $\begin{array}{ll}\text { Notes: } & \text { 1. Robust standard errors in parentheses. } \\
& \text { 2. } * * * \mathrm{p}<0.01, * * \mathrm{p}<0.05, * \mathrm{p}<0.1\end{array}$ & & & \\
\hline
\end{tabular}




\subsection{Internal Migration and Geographic Population Distribution}

China's population has been aging rapidly as the cohort of baby boomers in the 1950s and early 1960s has reached retirement age. The population aged 65 and above increased by 18.35 million over the last decade, from 100.45 million in 2000 to 118.8 million in 2010. Interestingly, regions in China have not been aging at the same rate.

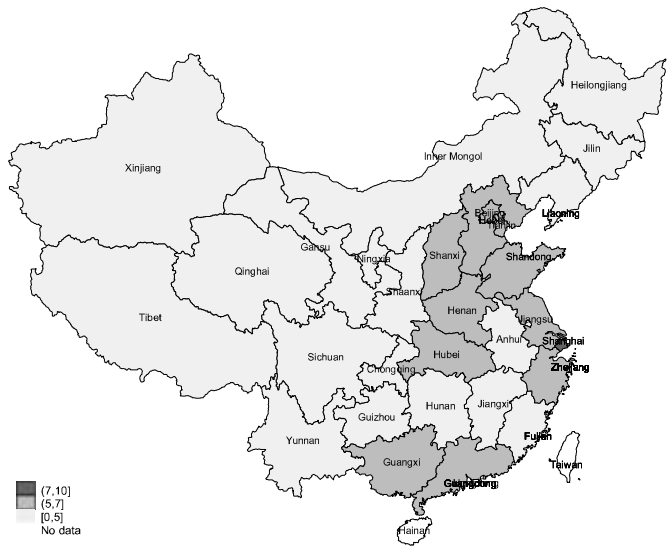

(A) Proportion of the population aged $65+(\%)$, 1982

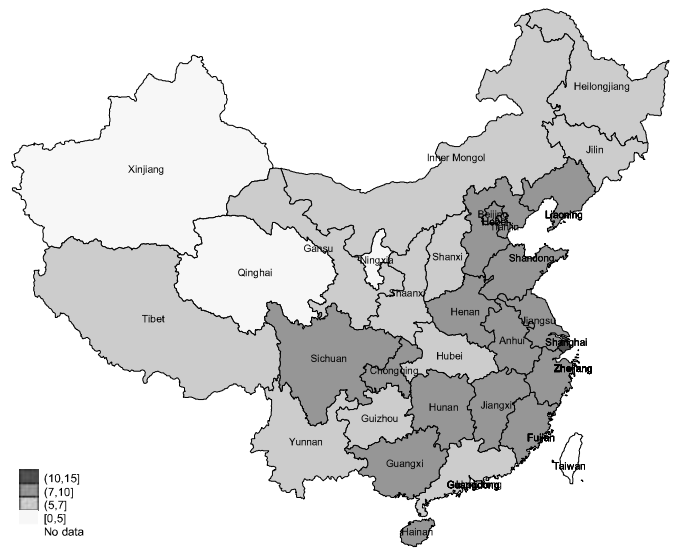

(C) Proportion of the population aged $65+(\%)$, 2000

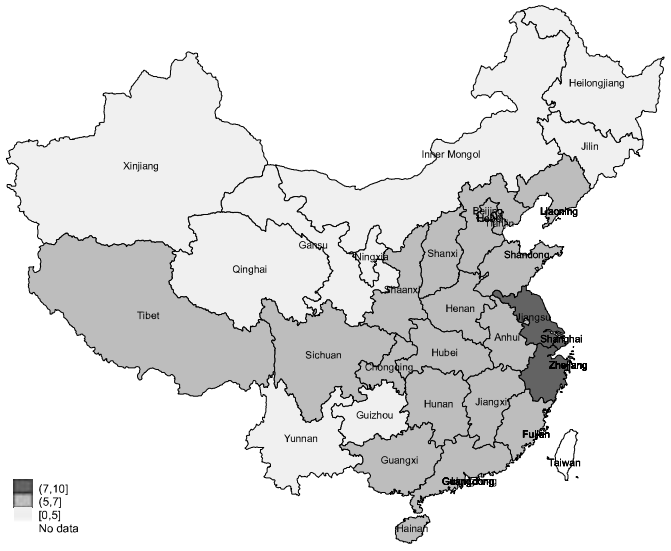

(B) Proportion of the population aged $65+(\%)$, 1990

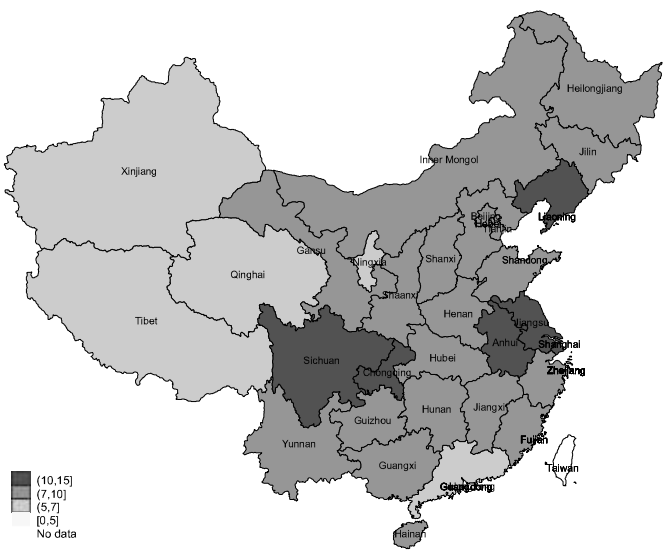

(D) Proportion of the population aged $65+(\%)$, 2010

Figure 7: Provincial Distribution Patterns of the Population Aged 65 and Over Note: The authors' own calculation from 1982, 1990, 2000, 2010 population census in China.

Figure 7 illustrates the provincial aging rates measured by the proportion of the population aged 65 and above over the period from 1982-2010. In eastern coastal China and the major urban centers, for example, Guangdong and Zhejiang province, the aging process has slowed because of the migration of young laborers from the inland provinces. However, in turn, the internal migration leads to a more serious 
aging challenge in inland provinces, for instance, Sichuan and Anhui province. As shown in Figure 8(B), the proportion of the population aged 65 and over increased by more than 2.5 percentage points in Anhui, Gansu, Guizhou, Sichuan and Chongqing over the period 2000-2010. Nevertheless, the proportion of the population aged 65 and over even decreased in Beijing, Shanghai, and Tianjin and increased less than 0.5 percentage points in Zhejiang and Guangdong. The internal migration of young laborers has shifted the aging problem from coastal provinces to inland provinces.

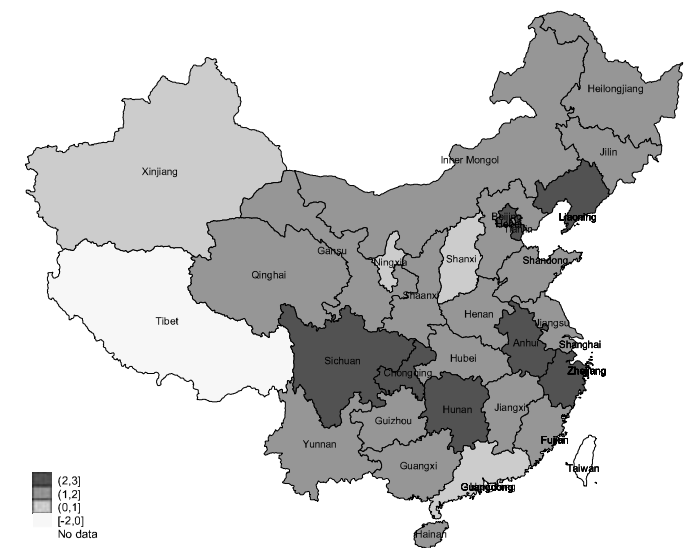

(A) Change in the proportion of the population aged $65+(\%), 1990-2000$

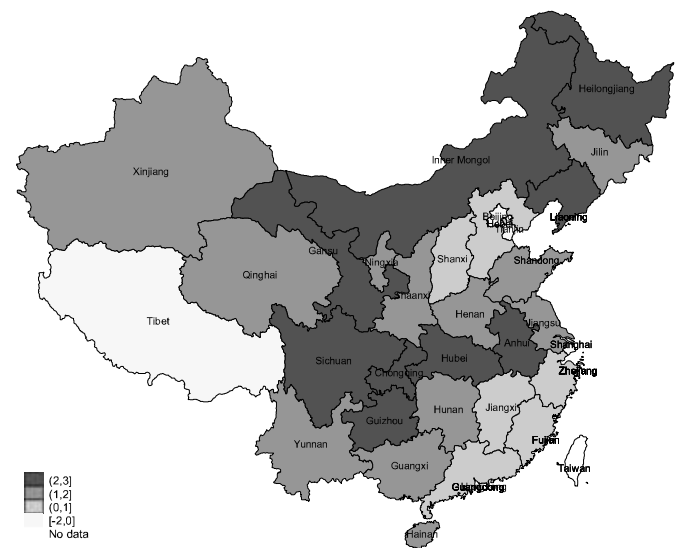

(B) Change in the proportion of the population aged $65+(\%), 2000-2010$

Figure 8: Provincial Change in Aging Rate (65 years and over)

Note: The authors' own calculation based on the 1990, 2000, 2010 population census in China.

The rural-urban migration in China has remarkably reshaped the geographic distribution of Chinese population in urban and rural areas. Figure 9(A) and (C) present the population pyramids for the urban and rural hukou populations (excluding migrants) separately for the year 2000. The urban hukou population pyramid is diamond-shaped, indicating a shrinking urban hukou population beginning at the time of the one-child policy. The pyramid for the rural hukou population shows a low number of births between the early 1970s and mid-1980s. Figure 9(B) and (D) report the population pyramids for the urban and rural population based on residence (including migrants). The pyramid for the urban residents has a wider base than the pyramid for urban hukou population. Nevertheless, the pyramid for the rural residents has a narrower base (especially for the population aged from 16 to 40). The internal 
migration of young laborers has shifted the aging problem from urban to rural areas. ${ }^{15}$ The aging problem and left-behind parents in the rural areas create considerable challenge for the old age support in rural China (Ao et al., 2016).

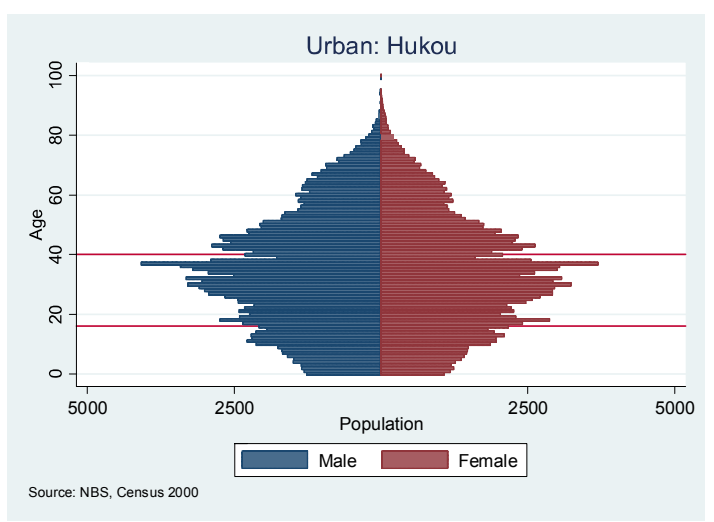

(A) Urban: Hukou

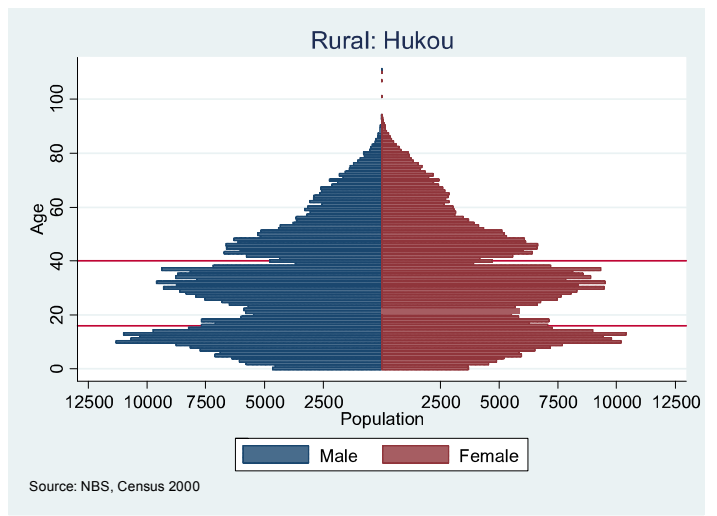

(C) Rural: Hukou

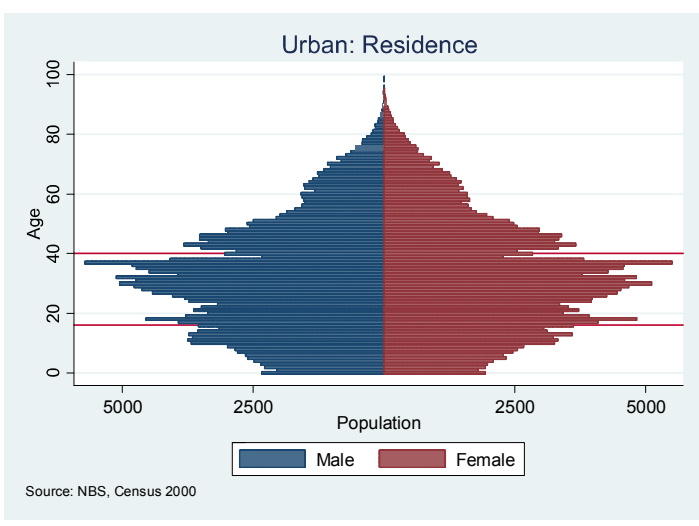

(B) Urban: Residence

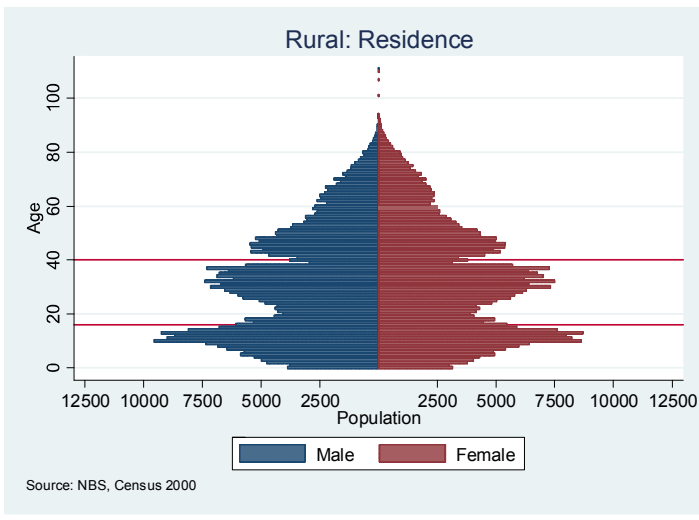

(D) Rural: Residence

Figure 9: Population Pyramid in Urban and Rural Areas, 2000

Note: The authors' own calculations based on one percent sample of the 2000 Population Census data.

The rural-urban migration also results in the shift of age distribution of China's employed population in the agriculture and manufacturing/service sectors. Figure 10 shows the age distribution of China's employed population by sector in 1982 and 2005. Because of the outflow of rural young laborers to cities, the population employed in the agriculture sector is aging rapidly. However, laborers in the manufacturing and service sectors are becoming relatively younger.

\footnotetext{
${ }^{15}$ For instance, the proportion aged 65 and above accounts for $10.12 \%$ of the total population in Shanghai in 2010. The proportion is $16 \%$ if migrants are excluded (Peng, 2011).
} 


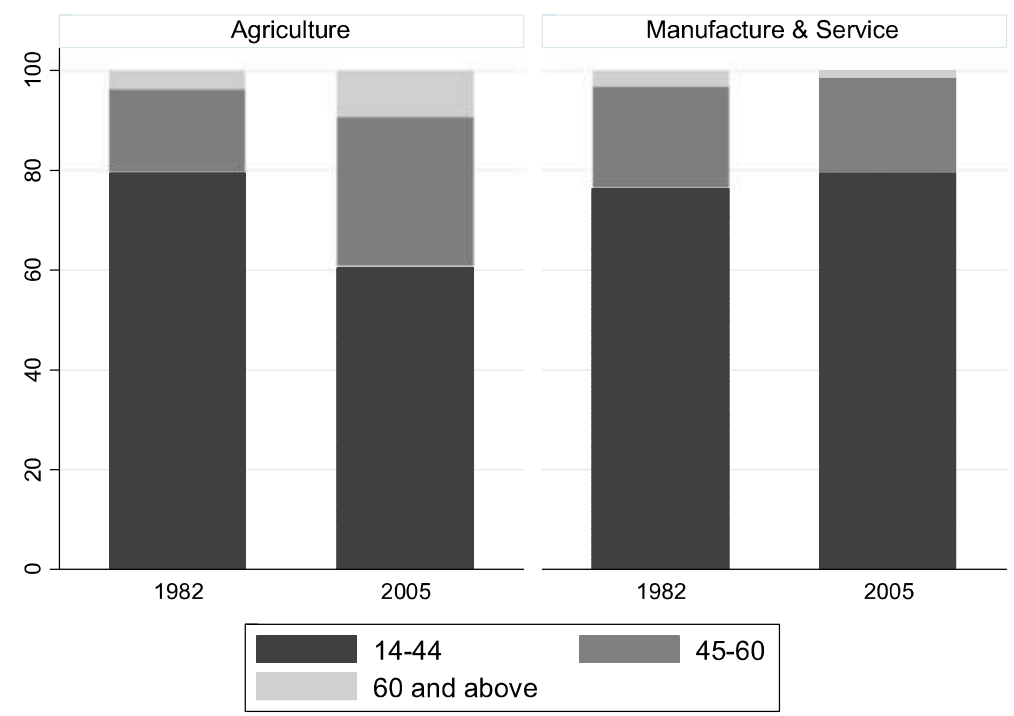

Figure 10: Age Distribution of Employed Population by Sector in 1982 and 2005

Note: The authors' own calculation based on the 1982 Population Census and mini-census in 2005 of China.

The aging process of urban areas eased because of migration inflows. The outflow of young laborers led to a more rapid aging process in rural areas. We further examine the relationship between migration flow and age structure in Table 4. The dependent variable is the share of the population aged 65 and above in 2005. The results indicate that the birth rate in the early 1980s has a negative effect on the aging rate, and its impact is smaller when taking internal migration into account. An increase in the in-migration rate is negatively associated with the proportion of the population aged 65 and over. However, an increase in the out-migration rate is positively correlated with the proportion of the population aged 65 and above.

In addition to the direct demographic effects on population distribution and shifting the age distribution towards a younger age, migration also tends to increase the fertility in urban areas, at least in the short run. In the long run, urbanization may change the fertility behavior of Chinese and further affect future demographic trends. For example, Zeng and Vaupel (1989) show that urbanization delays childbearing, reduces fertility and thus accelerates population aging. 
Table 4. Migration Flow and Age Structure

\begin{tabular}{|c|c|c|}
\hline Variables & $\begin{array}{c}\text { (1) } \\
\text { Share of population } \\
\text { aged } 65+\end{array}$ & $\begin{array}{c}(2) \\
\text { Share of population } \\
\text { aged } 65+\end{array}$ \\
\hline Birth rate in 1981-1985 & $\begin{array}{c}-0.22 * * * \\
(0.048)\end{array}$ & $\begin{array}{c}-0.18^{* * *} \\
(0.045)\end{array}$ \\
\hline In-migration rate in 2005 & & $\begin{array}{c}-1.87 * * * \\
(0.27)\end{array}$ \\
\hline Out-migration rate in 2005 & & $\begin{array}{c}9.11 * * * \\
(2.24)\end{array}$ \\
\hline \% of employment in manufacture in 1990 & $\begin{array}{l}-4.47^{*} \\
(2.56)\end{array}$ & $\begin{array}{c}0.89 \\
(1.93)\end{array}$ \\
\hline Average education in 1990 & $\begin{array}{l}-0.23 \\
(0.17)\end{array}$ & $\begin{array}{l}-0.22 \\
(0.17)\end{array}$ \\
\hline Log wage in 1990 & $\begin{array}{c}-1.61 * * \\
(0.81)\end{array}$ & $\begin{array}{c}1.04 \\
(0.71)\end{array}$ \\
\hline Log working-age pop in 1990 & $\begin{array}{c}0.38^{* * * *} \\
(0.14)\end{array}$ & $\begin{array}{c}0.39 * * * \\
(0.13)\end{array}$ \\
\hline Constant & $\begin{array}{c}23.2 * * * \\
(6.47)\end{array}$ & $\begin{array}{c}0.92 \\
(5.86)\end{array}$ \\
\hline Observations & 220 & 220 \\
\hline R-squared & 0.209 & 0.357 \\
\hline
\end{tabular}

\section{The New Two-child Policy and Its Consequences}

\subsection{Under-Going Policy Change}

The Fifth Plenary Session of the $18^{\text {th }}$ Communist Party of China Central Committee issued a communiqué on $29^{\text {th }}$ October, 2015, to declare the comprehensive implementation of a new family planning policy that allows a couple to have two children. The Standing Committee of the National People's Congress approved the "Amendment of the 'Population and Family Planning Law of the People's Republic of China" on $27^{\text {th }}$ December, 2015, and the amendment became effective on $1^{\text {st }}$ January, 2016.

The amendment advocated a couple to have two children and left specific 
measures decided by the local people's congresses. Previously, late marriage (male married no earlier than 25 and female married no earlier than 23) was rewarded with longer marriage and maternal leave, but this benefit was cancelled in the amendment. ${ }^{16}$ The amendment also stressed that a couple that voluntarily had only one child during the one-child policy period would still be rewarded and subsidized.

A few local people's congresses had approved the new policy, and other provinces are on their way to drafting policy details. While advocating two births, the new policy has in general imposed strict restrictions on three births. ${ }^{17}$

\subsection{Consequences of the Two-Child Policy}

\subsubsection{Fertility Trajectories}

More time is needed for a direct assessment of the fertility effects of the current two-child policy. We indirectly explore the effects according to evidence from (1) fertility desires, (2) two-child policies in history, and (3) fertility changes after a couple was allowed to have a second birth if some conditions were satisfied in previous years.

A number of studies have utilized data containing the desired number of births of respondents and have simulated fertility levels under specific family planning policies, such as a comprehensive two-child policy. However, simulation results substantially differ in the literature. Wang et al. (2013) predicted that, had the two-child policy been implemented in 2015, the total fertility rate of 2016 is unlikely to be higher than 1.93, which represents up to 6 million more births in 2016 due to the policy change. Soon afterwards, fertility rates would decline. Zhai et al. (2014) declared that the total fertility rates would increase to 3.0 after the implementation of the two-child policy, which means almost 20 million more births in a year.

Two-child policies exist in history, and estimates based on actual policies may

\footnotetext{
16 This revision intended to discourage late marriage and thus has induced more births. However, it has been under heat debate.

17 Remarried couples may have another child if the following two conditions are met at the same time: (1) either partner had at least one birth before remarriage; (2) both partners had no more than two births in total before and after remarriage. Couples who had two children but one of whom was disabled may also have a third child.
} 
offer more convincing conclusions than fertility desires. Two-child policies appeared in the 1970s for the first time, and then the one-child policy began around 1980. Wang (2014) estimated the fertility effects of all periods of China's family planning policies in history using a static regression model and a dynamic duration model and concluded based on the estimates that a woman born in 1970 would have 1.6-1.8 births in her entire life had the two-child policy in the 1970s continued after 1980, which is similar to the results of Wang et al. (2013) and implies that the two-child policy would have limited effects on fertility compared to the one-child policy. Figure 11 shows the fertility trajectories simulated by Wang et al . (2013).

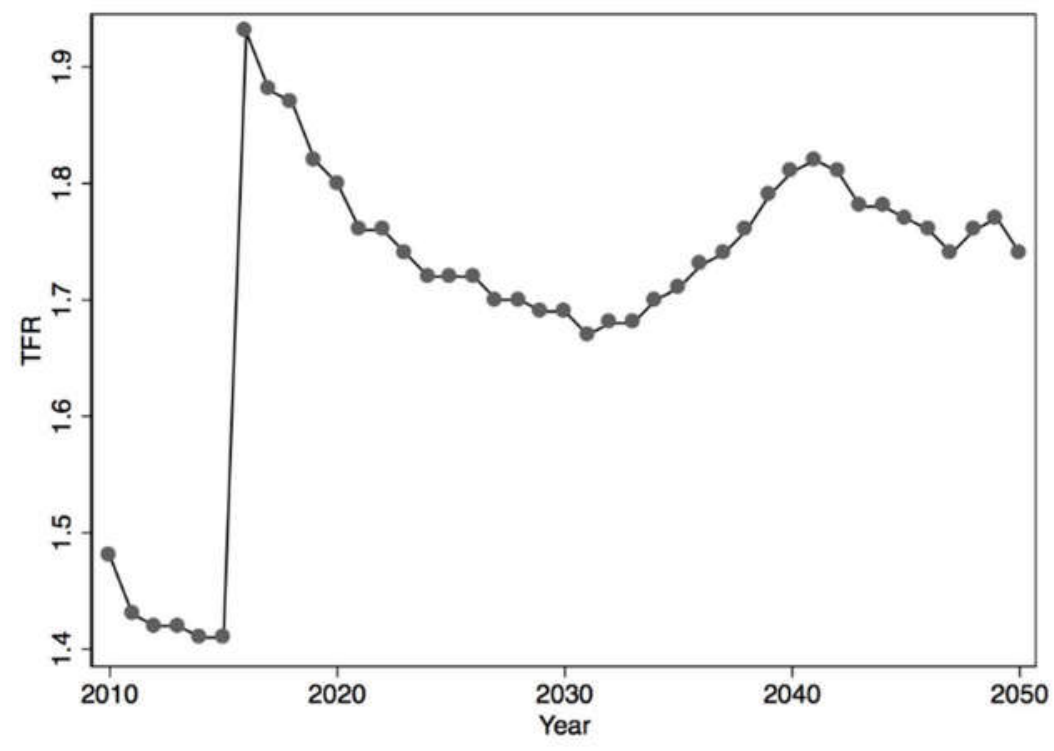

Figure 11: Fertility Trajectories with Two-Child Policy

Sources: Numbers from Wang et al. (2013)

Two-child policies appeared again around the mid-1980s. Beginning in the mid-1980s, while most regions allowed a couple to have a second birth if certain conditions were satisfied, four places launched comprehensive two-child policies: Chengde, Enshi, Jiuquan, and Yicheng. The first three are prefectural cities, and the last is a county. Gu and Wang (2009) collected a number of studies regarding the effects of the two-child policies in the four locations, and all have shown fairly limited effects compared to the one-child policy. Liang (2014) argued that only Yicheng was an appropriate location for studying the two-child policy because 
Chengde's policy was only implemented in the least developed mountain areas, Enshi had a large share of ethnic minorities and may not generate representative evidence, and Jiuquan's policy used to be interrupted. Qin and Wang (2015) used the synthetic control approach to identify the causal effects of Yicheng's two-child policy on fertility. Figure 12 shows the fertility effects of Yicheng's policy with the population data from local public security departments (left) and with random samples of the 1990 and 2000 censuses (right). In both figures, solid lines represent Yicheng's birth rates and dashed lines indicate the birth rates of the synthetic control county, which is constructed from all of the other counties in the same province such that the birth rates of Yicheng before 1985, the starting year of the two-child policy, match well with the weighted average birth rates of other counties. Both figures have shown nil short-term effects and limited, if any, long-term effects.

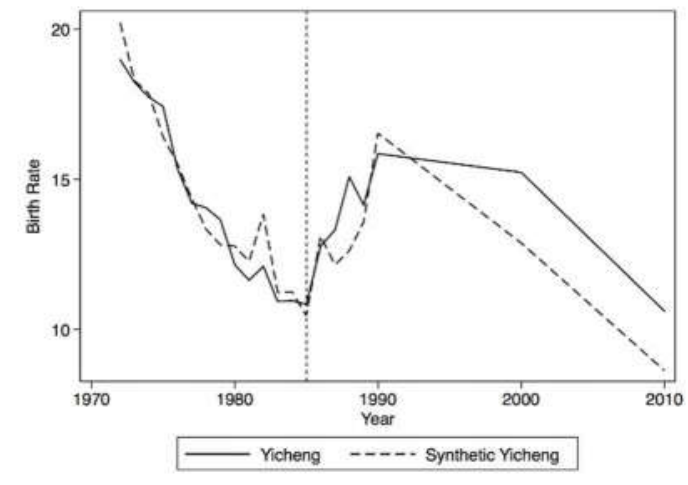

(A) Based on population data from local public security departments

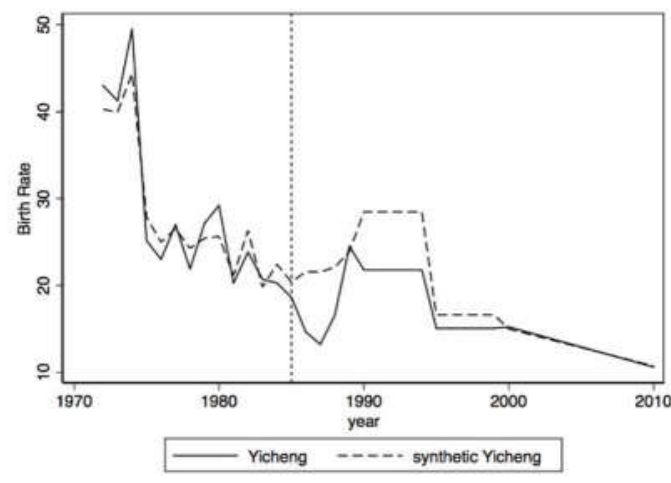

(B) Based on random samples of the 1990 and 2000 census

Figure 12: Fertility Effects of Two-Child Policy in Yicheng

Source: Qin and Wang (2015)

In 2014, almost all provinces allowed a couple to have a second birth if one partner is an only child. People born in the 1980s and early 1990s under the one-child policy played a major part in childbearing, and there were 11 million couples who qualified for a second birth. By September 30, 2015, approximately 1.85 million couples had applied for birth certificates for a second birth, only comprising a proportion of $16.8 \%$. It implies that the two-child policies are unlikely to increase the fertility sharply, at least when one partner is an only child, which will be more 
common in the future.

To summarize, most evidence supports limited fertility effects of the two-child policy. Fertility rates may rise prominently in the first several years of the new policy and then keep descending.

Table 5. Determinants of Having a Second Birth

\begin{tabular}{|c|c|c|}
\hline \multirow[t]{3}{*}{ Variables } & \multicolumn{2}{|c|}{$\begin{array}{l}\text { Whether having a second birth } \\
\text { during the year before the survey }\end{array}$} \\
\hline & (1) & (2) \\
\hline & OLS & Probit (Marginal Effects) \\
\hline Age dummies & Yes & Yes \\
\hline \multirow[t]{2}{*}{ Junior high school } & $-0.026 * * *$ & $-0.026 * * *$ \\
\hline & $(0.003)$ & $(0.003)$ \\
\hline \multirow[t]{2}{*}{ Senior high school or above } & $-0.057 * * *$ & $-0.070 * * *$ \\
\hline & $(0.005)$ & $(0.007)$ \\
\hline \multirow[t]{2}{*}{ Family monthly income (1000 yuan) } & $-0.0098 * * *$ & $-0.0107 * * *$ \\
\hline & $(0.0023)$ & $(0.0027)$ \\
\hline \multirow[t]{2}{*}{ Squared family monthly income } & $0.0006 * *$ & $0.0007 * *$ \\
\hline & $(0.0003)$ & $(0.0003)$ \\
\hline \multirow[t]{2}{*}{ Family size } & 0.00005 & 0.0004 \\
\hline & $(0.00099)$ & $(0.0009)$ \\
\hline \multirow[t]{2}{*}{ Healthy } & $0.040 * * *$ & $0.048 * * *$ \\
\hline & $(0.008)$ & $(0.013)$ \\
\hline \multirow[t]{2}{*}{ Sex ratio } & $0.116^{* * *}$ & $0.130 * * *$ \\
\hline & $(0.030)$ & $(0.029)$ \\
\hline Province dummies & Yes & Yes \\
\hline Observations & 44129 & 44129 \\
\hline R-squared & 0.044 & \\
\hline Log Likelihood & & -12370.599 \\
\hline
\end{tabular}

Notes: 1. Standard errors in parentheses. Coefficients in the Probit estimation stand for the partial effects of independent variables on the probability of having a second birth.

2. ${ }^{* * *} \mathrm{p}<0.01, * * \mathrm{p}<0.05,{ }^{*} \mathrm{p}<0.1$.

Other than the weak overall effects, the propensity of having a second birth may differ by characteristics of individuals, households and regions. Table 5 uses a random sample from the 2005 mini census of China conducted in November 2005 and 
restricts the sample to currently married rural Han Chinese women who were 15-50 years of age and had only one daughter before the November of 2004 to estimate how various factors affect their probabilities of having a second birth between November 2004 and November 2005. The estimation takes advantage of the policy relaxation that a rural couple was allowed to have a second birth if the first birth was a daughter.

Both OLS and Probit estimations have shown similar results. Age dummies are strongly associated with fertility. The probability of having a second birth rises with age, reaches the maximum around 32, and then decreases with age. Women who had a junior high school education were less likely to have a second birth than women whose education levels were primary school or below; the probability of having a second birth was even smaller for the women with a senior high school education or above. Family income was the summation of income of all family members that were at home during the survey, excluding the income of the current respondent. The control of family size makes family income and its square to capture income effects more precisely. Family income has non-linear effects on fertility. If the family monthly income was below 8,000 yuan, the probability of having a second birth went down with income, while above 8,000 yuan, women were more likely to have a second birth if family income was higher. Being healthy was positively related to having a second birth. As having a second birth, in the specific policy context, could be driven by both son preference and preference over family size, the regression further controls for sex ratio at the level of prefecture city, to separate son preference from family size preference. The coefficient of sex ratio shows that the higher a prefecture city's sex ratio was, the higher the probability of having a second birth would be for a woman living in the prefecture city, implying that regional son preference may urge individual women to have more births for the sake of having a son. Province dummies are significantly connected to women's fertility decisions, indicating that the probability of having a second birth was regionally heterogeneous due to some reasons that are not identified by the regressions. 


\subsubsection{Combined Impacts of the One- and Two-child Policy on the Current and Future Generation of Labor Force}

Existing literature has shown a small or even nil relationship between fertility and female labor supply in China (He and Zhu 2015, Li et. al 2015). In addition, the new two-child policy is unlikely to cause large fertility increases. Therefore, the effects of the two-child policy on labor supply of current working population, if any, tend to be small.

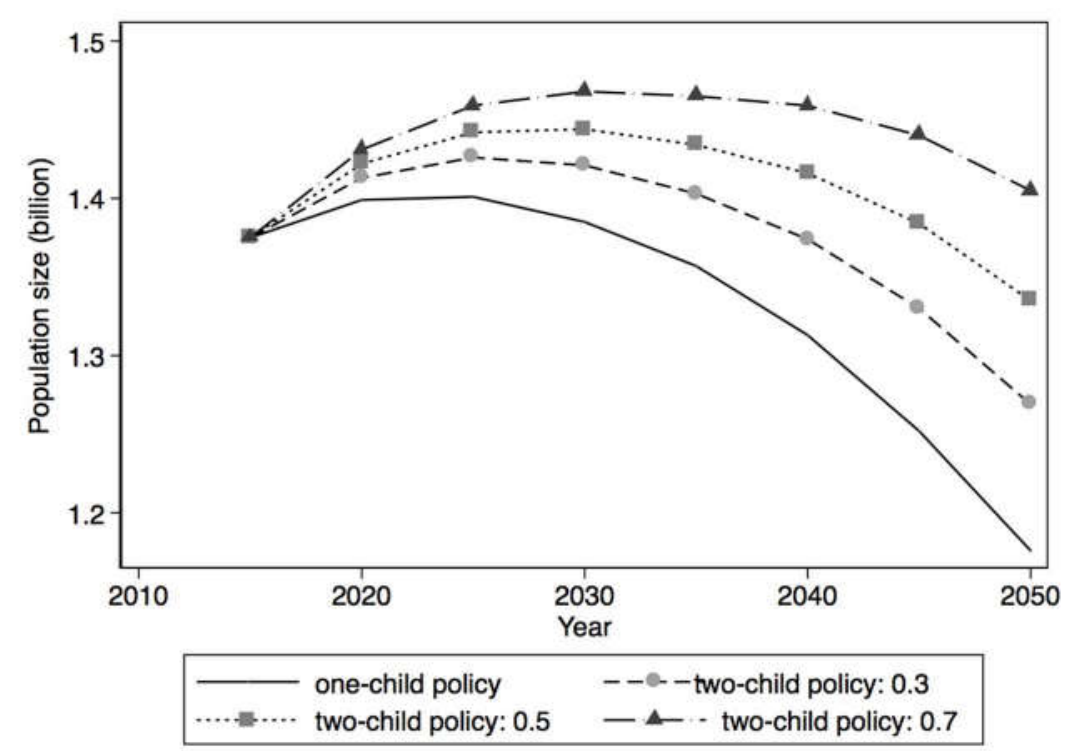

Figure 13: Simulated Population Size under the One- and Two-Child Policy

Note: The authors' own simulations. Detailed procedures are in Appendix C.

Figure 13 shows how China's population size would evolve under the two-child policy versus under the one-child policy. The figure assumes three different effects of the two-child policy on women's lifetime number of births compared to the previous one-child policy: $0.3,0.5$, and 0.7 , while 0.3 were around the estimates of McElroy and Yang (2000) and Wang $(2014,2015)$. In the first three years of the two-child policy, 0.5 was about the fertility increase, according to Wang et al. (2013). The upper bound of fertility increase can be regarded as 0.7 due to the two-child policy. Figure 13 implies that the two-child policy could, to some extent, increase the population and labor force. However, China's population is likely to begin shrinking 
no later than 2030, which was also illustrated by the simulation of Wang et al. (2013) (see Appendix Figure 2).

Figure 14(A) and (B) show the proportion of the population aged 65 and above (elderly population) and elderly dependency rates (the size of elderly population over the size of population aged from 15 to 64) over time under the one- and two-child policies. Similarly, the effects of the two-child policy on fertility compared to the one-child policy are assumed to be $0.3,0.5$, and 0.7 . It is clear that the two-child policy is far from pulling China out of ageing.

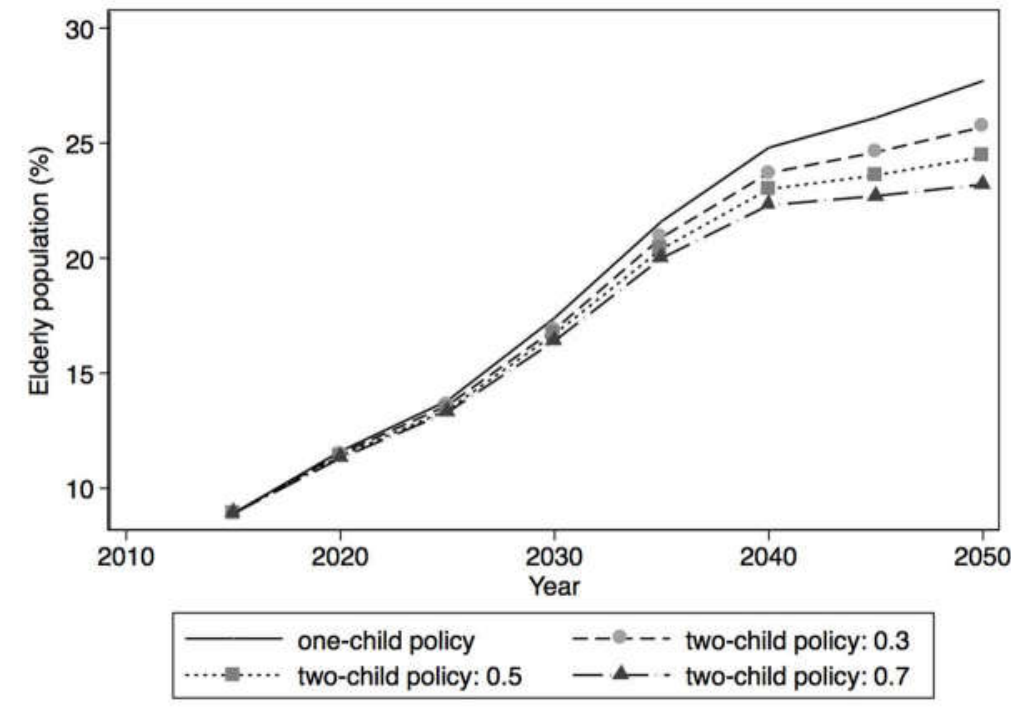

(A) Simulated Percentage of Elderly Population

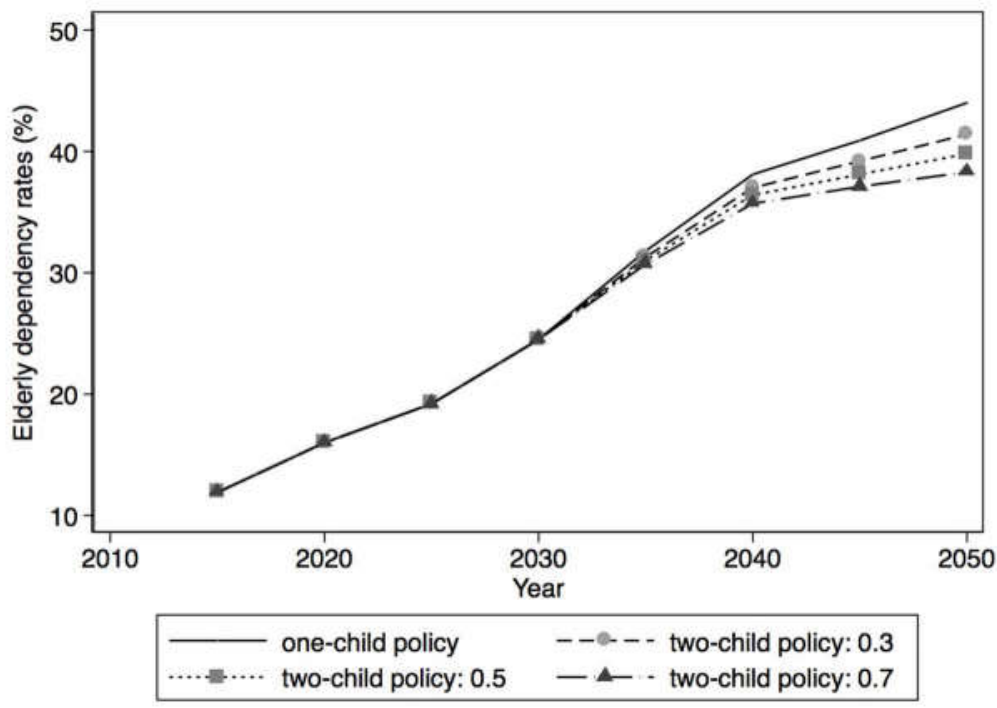

(B) Simulated Elderly Dependency Rates

Figure 14: Simulated Results under the One-child Policy Versus the Two-child Policy

Note: The authors' own simulations. Detailed procedures are in Appendix C. 
The sex ratio tends to be more balanced after the two-child policy is adopted. $\mathrm{Gu}$ and Wang (2009) indicated that Yicheng's sex ratio at birth used to be abnormally high but became normal after implementing the two-child policy, while other populous counties in the same province have shown rising sex ratios over time. The simulations in Figure 13 and Figure 14 are under the assumption of a balanced sex ratio at birth.

As discussed in Section 3.2.1, the one-child policy has small effects on schooling enhancement through the channel of quantity-quality trade-off. Therefore, relaxing the one-child policy to the two-child policy is unlikely to impair education improvement. In addition, as shown in Table 5, the effects of the one- and two-child policies on future generations of the labor force could depend on the characteristics of individuals, households and regions.

\section{Prospective Policies and Outlooks}

\subsection{Possible Future Policy Changes}

The two-child policy came into effect in 2016 partly because of the 2014 policy adjustment that allowed a couple to have a second birth if one partner was an only child and was not effective enough to raise fertility. If the two-child policy is not able to fit expectations, further policy relaxation is possible, such as the complete removal of the birth quota or even the implementation of pro-natal policies.

Figure 15 is from the report of the World Population Policies of the United Nations in 2013. The figure shows that the fraction of counties having birth control policies rose from 1976 to 1996 and then remained stable, while the proportion of counties with pro-natal policies has kept rising over time, from $9 \%$ in 1976 to $27 \%$ in 2013. It implies that aging is an international issue, and as a result, population policies have been turning from lowering fertility to raising birth rates. 


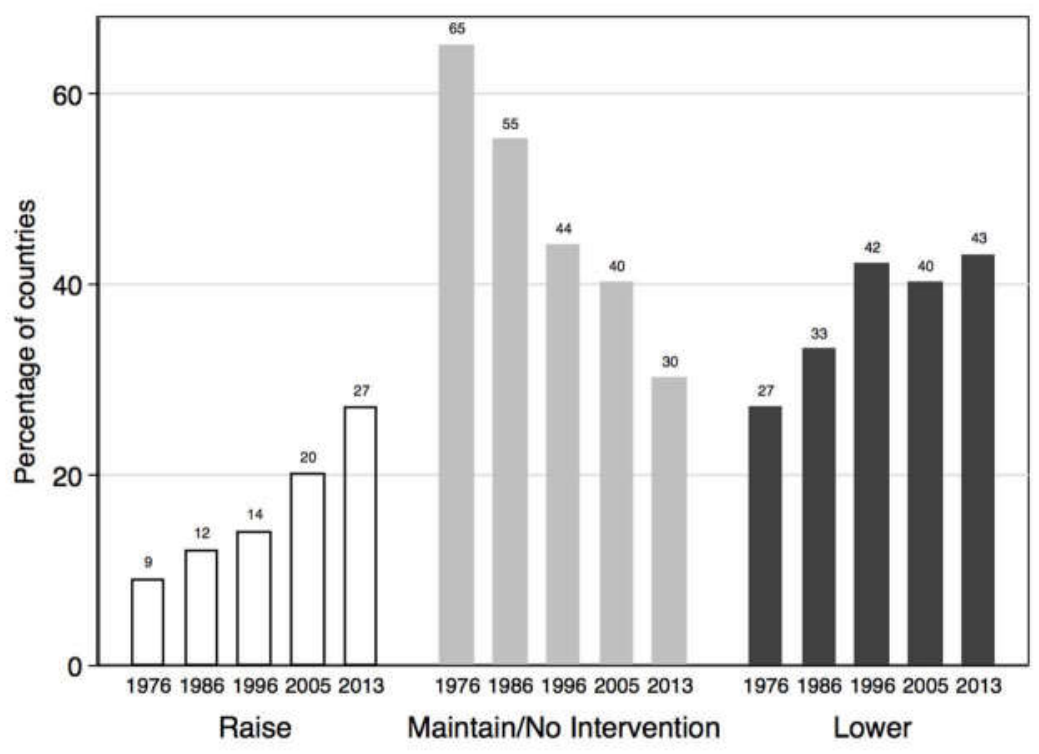

Figure 15: Percentage of Countries by Goals of Population Policies

Source: United Nations (2013)

Tang (2013) reviewed pro-natal policies in Japan, Singapore, South Korea, and Taiwan, which have similar fertility transitions and cultural traditions to China and hence could be examples for China's future policy adjustments. Japan's pro-natal policies began in 1989 when the total fertility rates reached 1.57. At the beginning, Japan's policy focused on lowering the costs of child-raising (e.g., the child allowance). Then, the policy gradually expanded to childcare, the employment of parents, and so on. Singapore's policy began in 1987, 12 years after its total fertility rates fell below the replacement level. The policy was multipronged, covering taxes, maternal leave, children allowance, and so on. South Korea did not take measures until 2005 , even though the fertility rate was as low as 1.1 before 2005 . South Korea encouraged a couple to have a first child one year after marriage and to have a second child when the mother reached 30 and subsidized the third and fourth births. Taiwan decided to encourage births in 2008 , four years after its total fertility rates reached 1.18. The policies involve childcare service, maternal leave, and support of families with minors and so on. To summarize, pro-natal policies in the four countries/regions attempt to raise fertility by taking measures of all aspects. 


\subsection{Outlooks of Future Policies}

\subsubsection{No Birth Control}

Similar to extrapolating the consequences of the two-child policy, China's fertility, demographic structure and labor market situations without birth control can be inferred by simulations from the estimates regarding China's past and current family planning policies.

Wang (2014) used a static regression model and a dynamic duration model to estimate the fertility effects of China's family planning policies. Simulations based on the estimates indicate that, had family planning policies never exist, a woman born in 1970 would have had about 2.5-3.5 children in her whole life. This is the upper bound of fertility levels if birth control is abolished in the future. First, fertility rates fall over birth cohorts. Wang (2014) implies that the fertility levels of women born around 1980 may further decline to approximately $2-3$ children over their lifetime. The rates would be even lower for younger cohorts who will consist of the major part of childbearing population in the future. Second, past family planning policies may indirectly shape the fertility behaviors and lower the birth rates of future generations by changing their fertility preferences, enhancing their human capital, and so on.

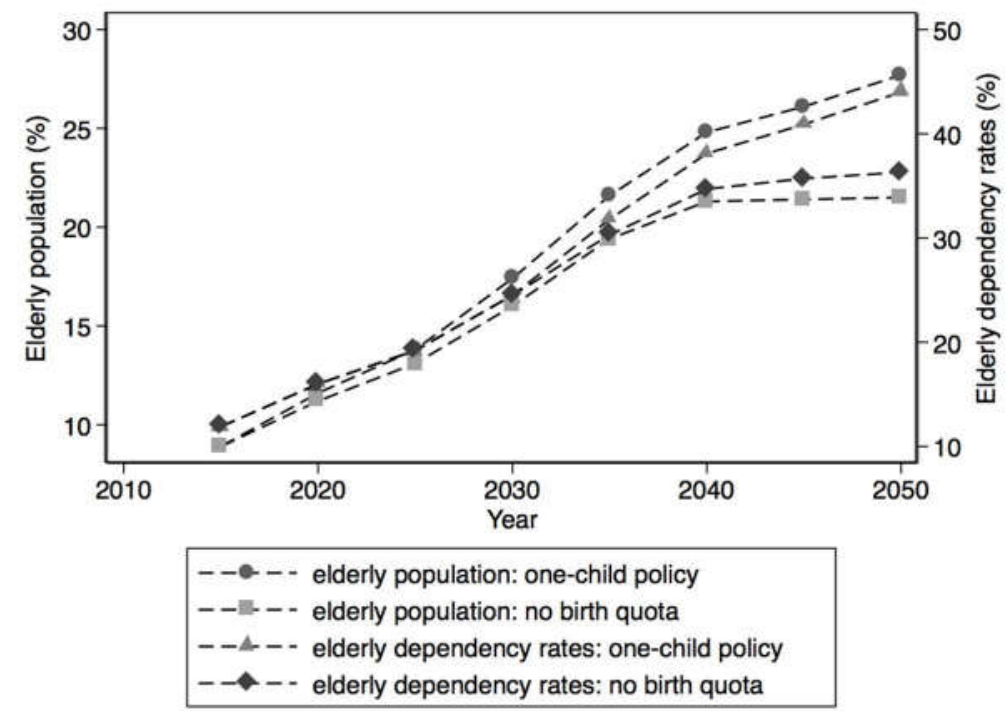

Figure 16: Simulated Percentage of Elderly Population and Elderly Dependency Rates

Note: The authors' own simulations. Detailed procedures are in Appendix C.

Assuming removing birth quota would lead to a lifetime fertility increase by 1 , 
which is a radical estimate given the experience of some East Asian countries, Figure 16 simulates how the percentage of elderly population and the elderly dependency rates would change over time had birth quota been absent since 2015, compared to the one-child policy. The abolishment of the birth quota would better address the aging problem than the two-child policy, but it still may not be enough.

\subsubsection{Pro-natal Policies}

We are not able to predict China's population and labor markets under birth encouraging policies without knowing the specific policy forms, but we may obtain implications from pro-natal policies in East Asian countries/regions. Tang (2013) summarized the effects of pro-natal policies in Japan, Singapore, South Korea and Taiwan. Japan and Singapore's policies have existed for more than 20 years, but their effects on fertility are trivial. More time may be needed for evaluating the policies in South Korea and Taiwan, but the policies thus far have not shown significant effects on fertility.

If pro-natal policies fail to increase fertility rates and, meanwhile, other measures, such as opening borders to international immigrants, are not applicable to China which has the largest population size in the world, the population would inevitably age more and more, and labor markets may encounter a shortage in the labor force if the industrial structure fails to transform properly. China should learn lessons from the four countries/regions and take action as soon as possible. It could be too late to make efforts when the fertility rates have already been at low levels for a long time. 


\section{References}

Angrist, J., 2002, How do Sex Ratios Affect Marriage and Labor Markets? Evidence from America's Second Generation, Quarterly Journal of Economics, 117(3), 997-1038.

Ao, X., D. Jiang and Z. Zhao, 2016, The Impact of Rural-Urban Migration on the Health of the Left-behind Parents, China Economic Review, 37, 126-139.

Becker, G. S. and H. G. Lewis, 1973, On the Interaction between the Quantity and Quality of Children, Journal of Political Economy, 8, 279-288.

Birdsall, N., and D. T. Jamison, 1983, Income and other Factors Influencing Fertility in China, Population and Development Review, 9, 651-675.

Bongaarts, J. and S. Greenhalgh, 1985, An Alternative to the One-Child Policy in China, Population and Development Review, 11, 585-618.

Borjas, G., 2000. Labor Economics. McGraw-Hill.

Blake, J., 1981, The Only Child in America: Prejudice versus Performance, Population and Development Review, 121, 271-282.

Cai, Y., 2010, China's Below-Replacement Fertility: Government Policy or Socioeconomic Development? Population and Development Review, 36(3):419-440.

Cameron, L., N. G. Erkal and X. Meng, 2013, Little Emperors: Behavioral Impacts of China's One Child Policy, Science, 339 (22), 953-957.

Chen, W., 2008, China's 30 Years of Reform and Opening Up and Population Transition, Population Research (in Chinese).

China Population Information Centre, 1984, Analysis on China's National One-per-thousand-population Fertility Sampling Survey.

Cooney, R.S., J. Wei and M. G. Power, 1991, The One Child Certificate in Hebei Province, China: Acceptance and Consequence, 1979-1988, Population Research and Policy Review, 10(2), 137-155.

Das Gupta, M., 2005, Explaining Asia's "Missing Women": A New Look at the Data, Population and Development Review, 31, 529-53

Goodkind, D., 2011, Child Underreporting, Fertility, and Sex Ratio Imbalance in China, Demography, 48(1), 291-316.

Ebenstein, A., 2010, The "Missing Girls" of China and the Unintended Consequences of the One Child Policy, Journal of Human Resources, 45(1), 87-115.

Feeney, G., F. Wang, M. Zhou and B. Xiao, 1989, Recent Fertility Dynamics in China: Results from the 1987 One-Percent Population Survey, Population and Development Review 15, 297-322. 
Greenhalgh, S., and J. Bongaarts, 1987, Fertility Policy in China: Future Options, Science, 235, 1167-1172.

Gu B., F. Wang, Z. Guo and E. Zhang, 2007, China's Local and National Fertility Policies at the End of the Twentieth Century, Population and Development Review, 33(1), 129-147.

Gu, B., and F. Wang, 2009, An Experiment of Eight Million People (in Chinese), Social Sciences Academic Press (China).

He, X. and R. Zhu, 2015, Fertility and Female Labor Force Participation: New Causal Evidence from Urban China, The Manchester School, forthcoming.

Heckman, J., 2005, China's Human Capital Investment, China Economic Review, 16(1), 50-70.

Huang, W, X. Lei and Y. Zhao, 2015, One-Child Policy and the Rise of Man-Made Twins, Review of Economics and Statistics, forthcoming.

Huang, W and Y. Zhou, 2015, One-Child Policy, Marriage Distortion, and Welfare Loss, IZA DP No. 9532.

Lavely W. and R. Freedman, 1990, The Origins of the Chinese Fertility Decline, Demography, 27(3):357-367.

Li Hongbin, Junsen Zhang and Yi Zhu, 2005,The Effect of the One-Child Policy on Fertility in China: Identification Based on the Differences-in-Differences, manuscript.

Li, H., J. Zhang and Y. Zhu, 2008, The Quantity-Quality Trade-off of Children in a Developing Country: Identification Using Chinese Twins, Demography, 45(1), 223-243.

Li, H., J. Yi, J. Zhang, 2011, Estimating the Effect of the One-child Policy on the Sex Ratio Imbalance in China: Identification Based on the Difference-in-Differences, Demography, 48(4), 1535-1557.

Li, H., L. Li, B. Wu and Y. Xiong, 2012, The End of Cheap Chinese Labor, The Journal of Economic Perspectives, 26(4), 2012, 57-74.

Li, H., J. Yi and J. Zhang, 2015, Fertility, Household Structure, and Parental Labor Supply: Evidence from Rural China, IZA discussion paper No. 9342, 2015.

Liang Z., 2014, China Population Problem (in Chinese), China Development Press (China).

Liu, H., 2014, The Quality-Quantity Trade-off: Evidence from the Relaxation of China's One-Child Policy, Journal of Population Economics, 27(2), 565-602.

McElroy, M. and D. T. Yang, 2000, Carrots and Sticks: Fertility Effects of China's Population Policies, American Economic Review papers and proceedings, 90(2):389-392, 2000.

Merli, G and H. Smith, 2002, Has the Chinese Family Planning Policy Been 
Successful in Changing Fertility Preferences? Demography, 39(3), 557-572.

Michelson, E., 2010, Family Planning Policy Enforcement in Rural China: Enduring State-Society Conflict? In J. C. Oi, S. Rozelle, \& X. Zhou (Eds.), Growing pains: Tensions and opportunity in China's transformation (pp. 189-226). Stanford: Shorenstein Asia Pacific Research Center, Distributed by Brookings Institution Press.

Merli, G. and A. Raftery, 2000, Are Births Underreported in Rural China? Manipulation of Statistical Records in Response to China's Population Policies, Demography, 37(1): 109-126.

National Bureau of Statistics (NBS), 2012, Tabulation on the 2010 Population Census of the People's Republic of China. Beijing: China Statistics Press (China).

Peng, X., 2011, China's Demographic History and Future Challenges, Science, 333, 581-587.

Poston Jr, D. L. and B. Gu, 1987, Socio-Economic Development, Family Planning and Fertility in China, Demography, 24, 531-551.

Qian, N., 2009, Quantity-Quality and the One Child Policy: The Positive Effect of Family Size on School Enrollment in China" NBER Working Paper w14973. In preparation for "Gender and Development" Oxford University Press.

Ravenstein, E. G.,1889, The Laws of Migration - Second Paper, Journal of the Royal Statistical Society, 52(2), 241-305.

Rosenzweig, M. R. and J. Zhang, 2009, Do Population Control Policies Induce More Human Capital Investment? Twins, Birth Weight and China's "One-Child", Review of Economic Studies, 76, 1149-1174.

Schultz, T. P. and Y. Zeng, 1995, Fertility of Rural China: Effects of Local Family Planning and Health Programs, Journal of Population Economics, 8(4):329-350.

Tang M., 2013, Choice for China's Population Policy: Lessons from East Asian Region, Population Research (in Chinese), Vol. 37, No. 6.

Tian X., 2009, Sixty Years of China's Population Policies (in Chinese), Social Sciences Academic Press (China).

Tien, H. Y., 1984, Induced Fertility Transition: Impact of Population Planning and Socio-Economic Change in the People's Republic of China, Population Studies $38: 385-400$

United Nations, 2013, World Population Policies 2013.

Wang, F., 2014, Essays on Family Planning Policies, Ph.D. Dissertation at the University of Southern California.

Wang, F., 2015, Using New Measures to Reassess the Fertility Effects of China's Family Planning Policies, unpublished manuscript. 
Wang, G., Y. Hu and L. Zhang, 2013, Adjustment of Family Planning Policy in China (in Chinese), Social Sciences Academic Press (China).

Wei, S. and X. Zhang, 2011, Sex Ratios, Entrepreneurship, and Economic Growth in the People's Republic of China, NBER Working Paper No. 16800.

Wolf, A.P., 1986, The Preeminent Role of Government Interventions in China's Family Revolution, Population and Development Review, 12(1), 101-116.

Yang, D. T. and D. Chen, 2004, Transformations in China's Population Policies, Pacific Economic Review, 9(3):269-290.

Zeng, Y. and J. M. Vaupel, 1989, The Impact of Urbanization and Delayed Childbearing on Pupulation Growth and Aging in China, Population and Development Review, 15(3), 425-445.

Zeng., Y., T. Ping, B. Gu. Y. Xu, B. Li and Y. Li, 1993, Causes and Implications of the Recent Increase in the Reported Sex Ratio at Birth in China. Population and Development Review, 19(2), 283-302.

Zeng, Y., 2007, Options for fertility policy transition in China, Population and Development Review, 33, 215-246.

Zhang, J., 1990, Socioeconomic Determinants of Fertility in China: A Microeconometric Analysis, Journal of Population Economics, 3(2), 105-23. 


\section{Appendix A: A Conceptual Model of Migration}

Suppose there are two cities in the economy, A and B. Each city has a representative firm producing a homogeneous good with the same production function $g\left(z_{i}, L_{i}\right), i=A, B$, where $L_{i}$ is the labor input in city $i$ and $z_{i}$ incorporates all technologies that affect labor productivity in city $i$. Let $\frac{\partial g\left(z_{i}, L_{i}\right)}{\partial z_{i}}>0, \frac{\partial g\left(z_{i}, L_{i}\right)}{\partial L_{i}}>0$, $\frac{\partial^{2} g\left(z_{i}, L_{i}\right)}{\partial^{2} L_{i}}<0$. Assume that each worker offers one unit of labor, and therefore, $L_{i}$ also represents the working-age population in city $i . L_{i}$ working-age people were born in the last period by the working-age people in the last period, $L_{i}^{-1}$, and the last-period working-age people phase out of the economy in the current period. We assume $L_{i}=L_{i}^{-1} f_{i}$, where $f_{i}$ is the last-period fertility rates in city $i$.

Trade in products is costless, which equalizes prices across regions. We normalize the price of products to be 1. Firms maximize profits as price-takers. Without migration between the two cities, the equilibrium real wage in city $i$ satisfies $w_{i}=\frac{\partial g\left(z_{i}, L_{i}\right)}{\partial L_{i}}$. Assume that migration imposes a cost $c>0$ on each migrant. There will be migration in the equilibrium if and only if $\left|\frac{\partial g\left(z_{A}, L_{A}\right)}{\partial L_{A}}-\frac{\partial g\left(z_{B}, L_{B}\right)}{\partial L_{B}}\right|>c$. Under such a condition, the equilibrium real wages with migration satisfies $\left|w_{A}^{m}-w_{B}^{m}\right|=c$. Without loss of generality, we assume $\frac{\partial g\left(z_{A}, L_{A}\right)}{\partial L_{A}}-\frac{\partial g\left(z_{B}, L_{B}\right)}{\partial L_{B}}>c$, and then people migrate from city $B$ to city $A$. This condition implies that technologies are more advanced in city $A$ or/and that the size of labor is smaller in city $A$.

Assume the size of migrants is $M$. In the equilibrium, we have

$$
\frac{\partial g\left(z_{A}, L_{A}+M\right)}{\partial\left(L_{A}+M\right)}-\frac{\partial g\left(z_{B}, L_{B}-M\right)}{\partial\left(L_{A}-M\right)}=c
$$

Therefore, $M$ can be expressed as the following function of other factors.

$$
M=m\left(z_{A}, z_{B}, L_{A}, L_{B}, c\right)=m\left(z_{A}, z_{B}, L_{A}^{-1}, L_{B}^{-1}, f_{A}, f_{B}, c\right)
$$

The migration flow between city $A$ and $B$ depends on technologies affecting labor productivity, the initial working-age population, birth rates in both cities and migration costs.

Suppose that the birth rate in city $B$ is $f_{B}=f$. City $A$ has a negative fertility shock, $f_{A}=f-d$. Then, we have 


$$
\frac{\partial g\left(z_{A}, L_{A}^{-1}(f-d)+M\right)}{\partial\left(L_{A}^{-1}(f-d)+M\right)}-\frac{\partial g\left(z_{B}, L_{B}^{-1} f-M\right)}{\partial\left(L_{B}^{-1} f-M\right)}=c
$$

Taking derivative with respect to $d$ on both sides, we can get

$$
\frac{\partial M}{\partial d}=\frac{\frac{\partial^{2} g\left(z_{A}, L_{A}+M\right)}{\partial^{2}\left(L_{A}+M\right)}}{\frac{\partial^{2} g\left(z_{A}, L_{A}+M\right)}{\partial^{2}\left(L_{A}+M\right)}+\frac{\partial^{2} g\left(z_{B}, L_{B}-M\right)}{\partial^{2}\left(L_{B}-M\right)}} L_{A}^{-1}>0,
$$

which implies that, given other factors being constant, a negative fertility shock in city $A$ increases the marginal product of labor in city $A$ and thus induces a higher volume of migration flow from city $B$ to city $A$. 
Appendix B: Supplementary Figures and Tables

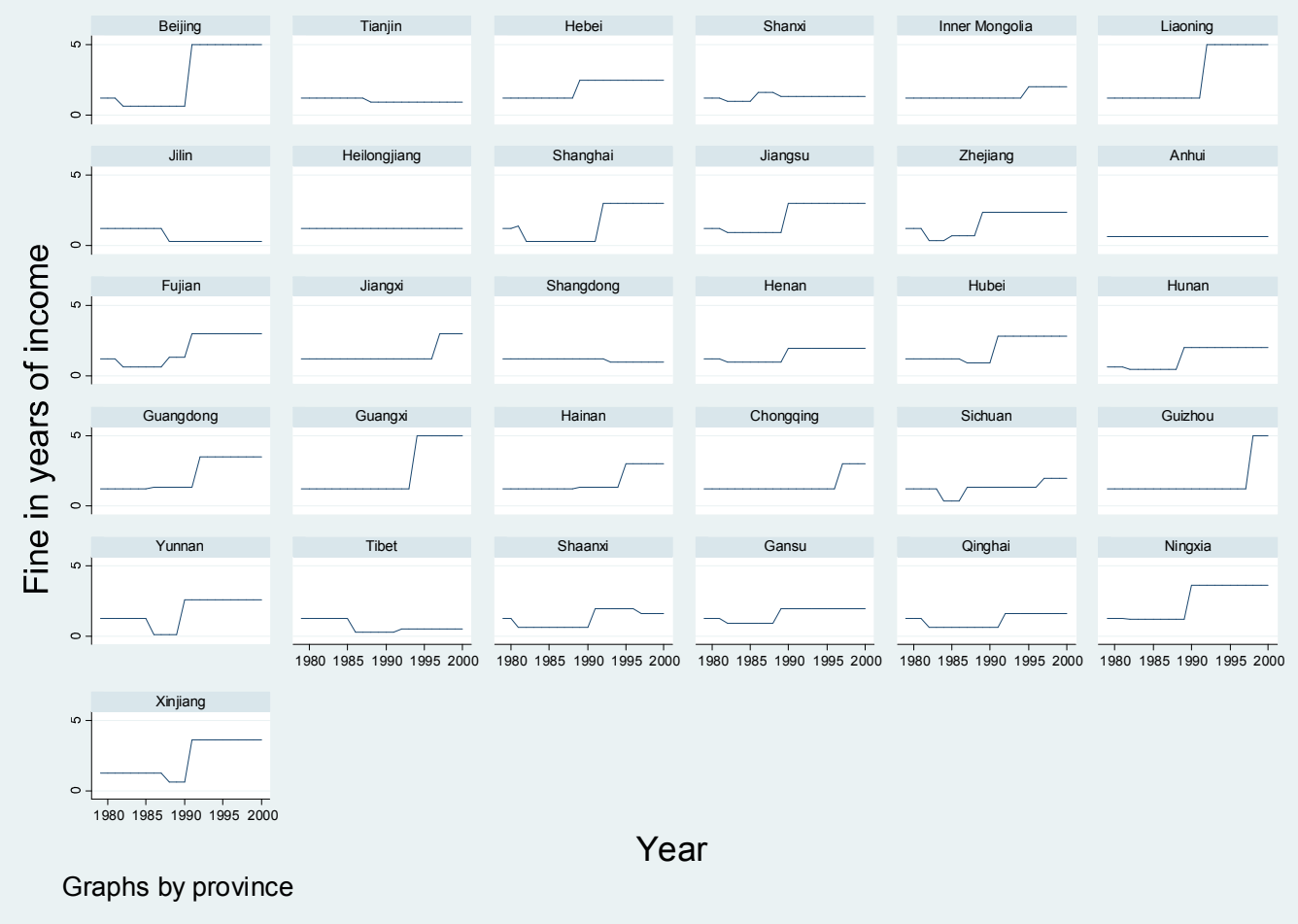

Appendix Figure 1: One-Child Policy Regulatory Fines in 1980-2000, by Province

Note: Data source is Ebenstein (2010)

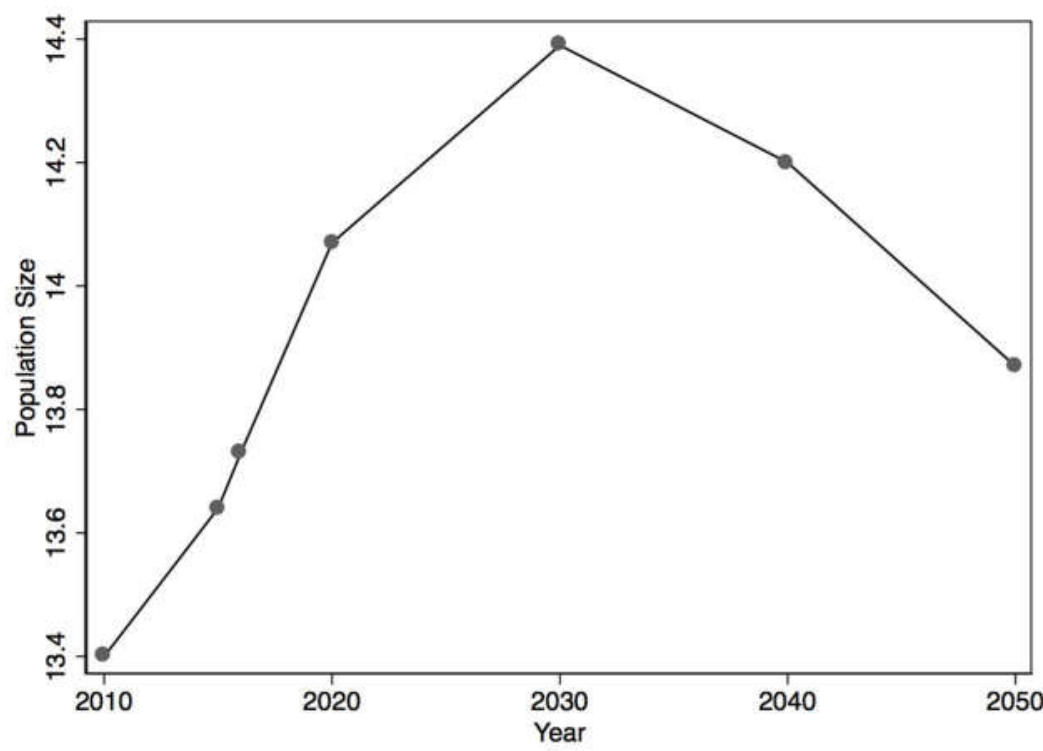

Appendix Figure 2: Simulated Population if the Two-child Policy Had Begun in 2015

Note: Data from Wang et al. (2013). Population size is measured in hundred millions. 


\section{Appendix C: Procedures of Simulations}

\section{C1. Simulations in Figure 4}

Step 1: Extrapolate the age and gender structure of the population in 1970 according to the population structure in the 1982 census by assuming no one died between 1970 and 1982 .

Step 2: Calculate the lifetime number of births for each birth cohort of women, starting from cohort 1918, based on actual birth records from the 1982, 1990, 2000 census and the 2005 mini census. Starting from cohort 1971, the number of births is assumed to decrease by 0.1 for every ten years of cohorts (e.g., 1.6 for birth cohorts 1971-1980, 1.5 for birth cohorts of 1981-1990, etc.).

Step 3: Had there been no family planning policies in history, the lifetime number of births for each cohort of women is assumed to increase by 1 . Moreover, the sex ratio at birth is assumed to be 1 had family planning policies not existed. Parameters of age-specific mortality rates are selected according to Chen (2008).

Step 4: Starting from the population structure in 1970, based on the parameters of birth rates and mortality rates, population can be simulated forward. Women's probability of childbearing is assumed to be different by age. The probability distribution is from Wang (2015).

\section{C2. Simulations in Figures 13 and 14}

Step 1: Predict the population structure in 2015 based on the population in the 2010 census, using the parameters introduced in $\mathrm{C} 1$. Then, rescale the predicted population size to the actual size in the end of 2015, keeping the population structure constant.

Step 2: Assume the effects of the two-child policy on the lifetime number of births to be $0.3,0.5$, or 0.7 . Other parameters remain the same as in $\mathrm{C} 1$. Then, population size, the share of elderly population and elderly dependency rates can be simulated forward.

\section{C3. Simulations in Figure 16}

All steps are the same with C2, except that women's lifetime births are assumed to increase by 1 had the birth quota been abolished. 